
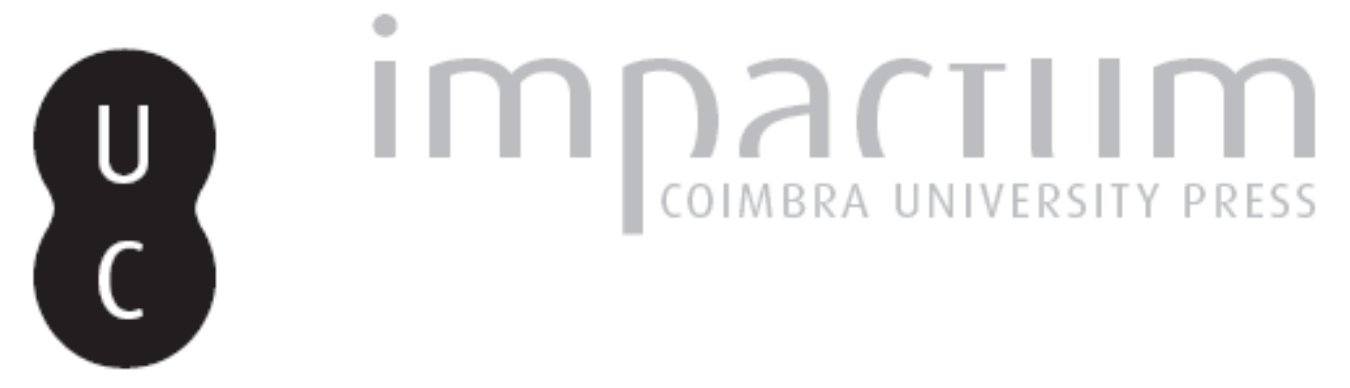

\title{
Espacios de uso funerario con indicación de medidas en las necropolis romanas
}

Autor(es): $\quad$ Rodríguez Neila, Juan Francisco

Publicado por: Imprensa da Universidade de Coimbra

URL persistente:

URI:http://hdl.handle.net/10316.2/45527

DOI:

DOI:https://dx.doi.org/10.14195/1647-8657_30_5

Accessed : $\quad$ 26-Apr-2023 14:29:23

A navegação consulta e descarregamento dos títulos inseridos nas Bibliotecas Digitais UC Digitalis, UC Pombalina e UC Impactum, pressupõem a aceitação plena e sem reservas dos Termos e Condições de Uso destas Bibliotecas Digitais, disponíveis em https://digitalis.uc.pt/pt-pt/termos.

Conforme exposto nos referidos Termos e Condições de Uso, o descarregamento de títulos de acesso restrito requer uma licença válida de autorização devendo o utilizador aceder ao(s) documento(s) a partir de um endereço de IP da instituição detentora da supramencionada licença.

Ao utilizador é apenas permitido o descarregamento para uso pessoal, pelo que o emprego do(s) título(s) descarregado(s) para outro fim, designadamente comercial, carece de autorização do respetivo autor ou editor da obra.

Na medida em que todas as obras da UC Digitalis se encontram protegidas pelo Código do Direito de Autor e Direitos Conexos e demais legislação aplicável, toda a cópia, parcial ou total, deste documento, nos casos em que é legalmente admitida, deverá conter ou fazer-se acompanhar por este aviso.

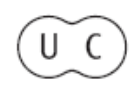


FACULDADE DE LETRAS

INSTITUTO DE ARQUEOLOGIA

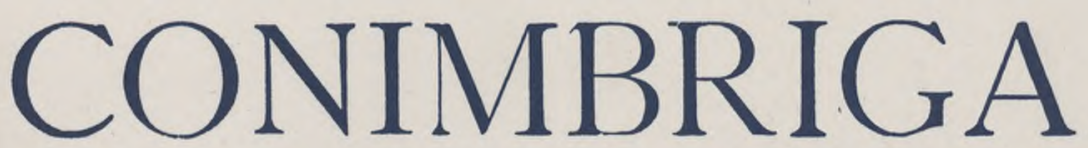

VOLUME XXX

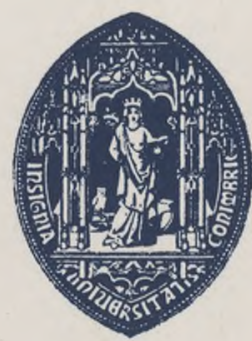

UNIVERSIDADE DE COIMBRA 


\section{JuAn Francisco Rodríguez NeILA}

Profesor en la Universidad de Córdoba

\section{ESPACIOS DE USO FUNERARIO CON INDICACION DE MEDIDAS EN LAS NECROPOLIS ROMANAS \\ «Conimbriga» XXX (1991), p. 59-94}

Sumario: Este estudio se centra en un peculiar de las necrópolis romanas, los espacios de uso funerario cuyas medidas se indicaban en las correspondientes inscripciones (cipos señalizadores, epitafios). Se estudian las razones que motivaron tal costumbre, las variantes que presenta, los elementos físicos que servían para delimitar las tumbas. También se analizan las extensiones de los acotados funerarios indicados en los datos epigráficos, comparando cuantitativa y cualitativamente la realidad hispana con la información proporcionada por algunas necrópolis italianas. Finalmente se evalúa la posibilidad de entender los datos sobre extensión de espacios funerarios como indicadores del "status" económico de las personas allí enterradas.

Summary: This study concerns a particular aspect of the Roman necropolis, the spaces for funeral uses, whose sizes were sometimes indicated in the respective inscriptions (boundary stones, epitaphs). The reasons for that habit, the different forms presented and the physical elements serving to delimit the tombs are considered. The extension of the funeral plots, according to the epigraphical sources, is also analysed, comparing qualitatively and quantitatively the Spanish evidence with the data furnished by some Italian necropolis. Finally the possibility of understanding the data on the sizes of the grave spaces as indicating the economic status of the people there buried are examinated. 
(Página deixada propositadamente em branco) 


\section{ESPACIOS DE USO FUNERARIO CON INDICACION DE MEDIDAS EN LAS NECROPOLIS ROMANAS}

En las necrópolis romanas las dimensiones de los espacios de uso sepulcral eran con frecuencia indicadas en los epitafios o en cipos terminales ubicados en los extremos de los acotados. Tal costumbre, atestiguada en muchas partes, trataba de prevenir los abusos de una ocupación ilegal. Así se ponía de relieve el derecho de propiedad sobre una parcela de terreno, sobre la que se ejercitaba el ius sepulchri del propietario y fundador, en previsión de reclamaciones o usurpaciones.

Cuando se trataba de tumbas que podían quedar aisladas entre los fundi circundantes, convenía acotarlas claramente con relación a aquéllos con vistas, sobre todo, al ejercicio del iter ad sepulchrum. También, como observa Geraci $(1969,376)$, la indicación de las medidas del área sepulcral, junto a una obra de albañilería externa (muro, balaustrada, etc.), que no siempre existía, eran los elementos que en sustancia determinaban qué porción de un fundus privado estaba ocupada por tumbas, constituyendo res religiosa inalienable e inviolable y, por tanto, si dicho fundus podía ser íntegra o parcialmente objeto de libre comercio (De Visscher, 1963, 71 y n. 24.). Igualmente, a tenor de las diversas iniciativas (imprecaciones, multas, etc.) con las que se intentaba prevenir la violación de las áreas funerarias, hecho por lo demás frecuente, una especificación lo más exacta posible de sus medidas, y una constatación visible de sus límites mediante cipos u otros elementos delimitadores, podían servir como elementos disuasorios ante cualquier forma de intrusismo sepulcral Q.

(9 Así lo vemos en CIL, VI, 28449: $a b<h>a c$ maceri[a i]n circuito pedes tres recede.

Conimbriga, 30 (1991), 59-94 


\section{ACOTADOS FUNERARIOS CON INDICACION DE MEDIDAS.}

Los acotados funerarios hispanos con indicación de medidas aparecen tanto en necrópolis suburbanas como en zonas rurales. En el segundo caso se trata de tumbas aisladas en fundi privados concretos, no pertenecientes a una gran necrópolis, tumbas que por las razones ya expuestas convenía individualizar respecto a su entorno dentro de la misma finca.Su principal forma de protección estribaba en su cualidad de loci religiosi. Pero la principal respuesta a las cada vez más crecientes exigencias espaciales de la "demografía de la muerte" fue la creación de lotes funerarios uniformes, un rasgo destacable de la periferia de las ciudades romanas.

La regularidad en las descripciones espaciales de los terrenos sepulcrales, y el carácter "standard" de sus medidas $(10 \mathrm{x} 10$ pedes y 12 x 12 pedes son las más frecuentes con mucho), muestran que la práctica de los acotados funerarios era un fenómeno coherente que respondía a ambientes sociales y medios físicos similares. La escala de elección en las áreas funerarias acotadas, así como la geométrica exactitud de su configuración, muestran que no estamos ante terrenos inmersos en planteamientos topográficos o desarrollos catastrales fortuitos, sino ante lotes particulares mantenidos aparte para esta clase de utilización - ya por emprendedores individuos, las ciudades o el Estado - , y vendidos en parcelas regulares a compradores individuales, o bien donados munificentemente para su uso funerario por parte de los sectores sociales menos pudientes (Purcell, 1987, 38).

El uso de indicar las medidas del área funeraria mediante cipos está atestiguado ya en un discurso de Cicerón \{Phil., IX, 7, 17) y en un pasaje de Horacio \{Sat., I, 8, 12-13), o sea, en la segunda mitad del s.I a.C., siendo característico de época augústea. Una inscripción de Castrimoenium (CIL, XIV, 2467), que hace explícita referencia a lo mismo, está datada en el 31 d.C. Los epígrafes hispanos que recogen las medidas in fronte!in agro de los acotados sepulcrales corresponden prioritariamente a los siglos I-II d.C.

Ciertamente, muchas inscripciones funerarias no indicaban las dimensiones del espacio sepulcral, lo cual, según Purcell (1987, 37 s.) tiene varias explicaciones. Algunas podían corresponder a columbaria $\mathrm{o}$ otros tipos de enterramientos comunales. $\mathrm{O}$ bien podía tratarse de tumbas ubicadas en áreas espaciosas donde no había escasez y, por tanto, competencia por el espacio. Otras podían proceder de propiedades 
particulares ajenas a cualquier tipo de regulación espacial, que accidentalmente se convertían en lugares de enterramiento. También los acotados funerarios podían tener límites físicos tan explícitos que hicieran innecesaria la indicación "in situ" de las medidas. Pero la existencia de un estimable porcentaje de epígrafes que informan sobre las medidas de acotados funerarios cuadrados o rectangulares, constituye un fenómeno "sui generis" que requiere un análisis particular por sus hipotéticas implicaciones sociales y económicas.

El área sepulcral se expresaba en dos dimensiones :1a parte ubicada a lo largo de la vía por la que se accedía y que le servía de límite frontal (frons); y en profundidad, en dirección hacia el interior del campo (ager). Las medidas del acotado funerario eran dadas en piés romanos, unidad que para nuestros cálculos hemos redondeado en $\left.30 \mathrm{cms} .{ }^{2}\right)$. La indicación de las medidas iba generalmente en caso ablativo, como un complemento de lugar con referencia a la voz locus, que suele suprimirse, se abrevia en $L$ (ocus), o incluso es reemplazada por el término $H o c$, como vemos en:

\section{n. 12 HOC IN.F.P./IN AGR.P.}

La referencia epigráfica espacial in frontelin agro se expresaba normalmente en dicho orden y de modo abreviado, indicándose tras dichas palabras las medidas correspondientes. Lo que de una forma totalmente desarrollada constituiría la fórmula locus in fronte pedes... (tot), in agro pedes... (tot), se presenta epigráficamente con una gran cantidad de variantes, desde las más desarrolladas hasta las más escuetas. También podía invertirse el orden normal de las medidas, señalándose primero la cifra de piés in agro, y luego la de piés in fronte (nn.47, 50, 64). O incluso repetirse la indicación in fronte para señalar las medidas de dos lados del acotado funerario, que sirven para conocer la extensión total del espacio sepulcral, en este caso de forma cuadrada. Así lo vemos en el n.6 con un espacio de $16 \times 16$ piés, o el n.38 con un espacio de $15 x$ ? piés (quizás también 15 piés). Posiblemente se tratara de acotados sepulcrales que, por ubicarse en una esquina entre dos

(2) Un pié romano $=30,5 \mathrm{cms}$. da W.F.RICHARDSON, Numbering and Measuring in the Classical World, Auckland,1985,28.CÉBEILlaC (1971,102 n. 1) redondea en $30 \mathrm{cms}$. el pié romano que evalúa en $295,78 \mathrm{~mm}$. 
caminos o vías, presentasen dos frontes. En el n. 47 seguramente la indicación de ambas medidas se completó con el verbo $s$ (unt).

Para especificar un área cuadrada se empleaba, aunque esporádicamente, no la fórmula completa in fronte $p$./in agro p., sino otra más simple, Q.Q.V.P. (quoquoversus pedes), que Donati (1965, 90), por ejemplo, constata varias veces en los talleres epigráficos de Bolonia, y que aparece ya en una referencia ciceroniana $\left(^{3}\right)$, aunque en Hispania está escasamente atestiguada:

- n. 4 (Alcaudete): l(ocus) p(edum) q(uo)q(uo)v(ersus), un cuadrado de $25 \times 25$ piés.

- n. 75 (Tucci): $q($ uo)q(uo)v(ersus) l(ocus) p(edum), un cuadrado de $12 \times 12$ piés.

Hay otra fórmula, P(edes) Q(uadrati), no constatada en Hispania, que sirve para indicar la amplitud del área sepulcral, no su forma. Ya hemos visto cómo la repetición de la medida in fronte puede emplearse para señalar la extensión de un área sepulcral cuadrada.

En ocasiones se da solamente una de las dos medidas, por lo general la correspondiente a la frons del área funeraria. En la epigrafía boloñesa, como constata Donati (1965, 95-96), los espacios sepulcrales con indicación de ambas dimensiones superan ampliamente en número a los que solamente incluyen una, siendo entre los segundos más abundantes los que aportan la medida in fronte.

Posiblemente se omitía la indicación in fronte o in agro pedes (tot) cuando, por existir en los demás lados elementos delimitadores lo suficientemente explícitos (balaustrada, muro, fosa, etc.), se hacía realmente innecesaria la constatación del dato (cfr. nn. 2, 76, 77, 78, $79,81,82)$. Así sucedía cuando una tumba se erigía en una zona ya rodeada por otros monumentos que delimitaban con claridad su extensión. O cuando correspondía a columbarios con confines bien definidos. También se hacía innecesario consignar el dato cuando el enterramiento se ubicaba aisladamente en una propiedad rural donde no había escasez de espacio, como el caso recogido en una inscripción de Ostippo, que menciona a un individuo que sepultus est fundo suo pago Singiliens(i) (Curchin, 1985, 339).

(3) Cfr.STYLOW, 1983,293,quien destaca este uso epigráfico como algo característico de la zona S.E. de la provincia de Córdoba y zona colindante de Jaén,práctica que se iría perdiendo en el curso del siglo I d.C. 
En los epígrafes hispanos recopilados nunca faltan las medidas in fronte, y como ese término se indica con relación a una vía de acceso, ello confirma que ese camino respecto al cual se hacía valer el iter ad sepulchrum era requisito esencial para fijar un acotado funerario, que podía quedar "empotrado" entre otros acotados por tres de sus lados, quedando abierta al camino la frons.

También encontramos la indicación de una sola dimensión, sin especificación in fronte o in agro. Tal es el caso de aquéllos epígrafes con la expresión L. P., que se interpreta como L(ocus) P(edum) oL(oci) $P(e d e s)$, siguiendo a continuación una cantidad, que debemos entender como la medida in fronte del acotado funerario correspondiente $\left({ }^{4}\right)$ :

n. 3. Alcalá la Real:L(ocus) p(edum) $X V$.

n. 5. AlcaudeterTföd) $P$ (edes) XII.

n. 28. Baena:L(ocus) p(edum) $C X X$.

n. 55. lgabrum:L(ocus) p(edum) $L V$.

n. 61. MetellinumiLfocw ${ }^{\wedge} p($ edum $) X I I$.

n. 62. Metellinum:L(ocus) $p$ (edum) XII.

n. 66. OssigiiLfoc/j $p$ (edes) $X X X$.

n. 69: Puente Genil:L(ocus) $p$ (edum) $X V$.

n. 80: Tucci:L(ocus) $p$ (edum) $X$.

n. 85: Tucci:L(oci) P(edes) $L X X X V$.

n. 91: Villar de Rena:L(ocus) p(edum) XVI.

Parece evidente, a tenor de lo expuesto, que para la indicación de medidas de áreas funerarias no había usos fijos en los talleres epigráficos, e incluso cabe constatar algunos más no documentados en Hispania $\left({ }^{5}\right)$.

En ciertos casos $(\mathrm{nn} .28,66,85)$ en que vemos epígrafes que solamente indican medidas in fronte!in agro, o únicamente una de ellas, pero sin nombres propios ni otros datos sobre personas allí enterradas, podemos pensar que estamos ante cipos terminales ubicados en diversos

(4) Cic.,Phil.,IX,7,17:1/tique locum sepulcro in campo Esquilmo C. Pansa, consul, seu quo in loco videbitur,pedes triginta quoquoversus adsignet,quo Ser.Sulpicius inferatur...

$\left.{ }^{5}\right)$ A título de ejemplo tenemos los siguientes:

- ILS, 8319:in fronte...retro $p$.

- CIL, V,3500:m front.p.XV in recess.p.XII.

- ILS, 8349'.habet autem agellus conclusus latitiae p.L XXV longitiae p.CXXXVII. 
confines del acotado funerario, diferentes de los epitafios, los cuales irían situados junto a los sepulcros. Tales cipos o mojones servían para delimitar con máxima precisión un espacio concreto, a fin de reservarlo para usos funerarios futuros (así el n. 92). Ello está confirmado por explícitas referencias en algunos documentos epigráficos $\left(^{6}\right)$.

La existencia de cipos terminales de las áreas sepulcrales demuestra, de hecho, que éstas podían superar en amplitud a las construcciones erigidas en su interior, es decir, que el monumento funerario, fuese del tipo que fuese, podía con frecuencia ocupar sólo una parte de la totalidad del espacio reservado a tales fines (Geraci, 1969, 376), dedicándose a veces el resto a horti, construcciones anejas, etc.

El número de cipos podía variar.A falta de otros términos de referencia (balaustradas, muros, etc.) para acotar visiblemente el espacio funerario, cuatro cipos dispuestos en las esquinas del área sepulcral podían servir como límites, aunque su número podía ser mayor $\left.{ }^{7}\right)$. La ley castigaba el desplazamiento de los cipos colocados para deslindar los terrenos, y también el hurto de los mismos para aprovecharlos con

$\left.{ }^{6}\right)$ Pueden servir de ilustración al respecto:

- ILS,7862 (Roma):un tal C. Licinius Hilarus, cippos d(edit) d(edicauit) o d(onauit) para una tumba cuyas medidas se indican a renglón seguido.

- ILS,7993 (Asís):epígrafe que hace referencia a la tumba que erigió un tal C. Vesprius Eros para sí y su mujer Leria, añadiéndose esta indicación:^post cippum ossuis locus.

- ILS,4998 (Roma): locus sepulchri continet per cippos dispositos iuger. quattuor...

- An.Ep., 1980,505 (Venetia): quem locum sepolturae cum suis terminis...

- ILS,8207b\_Stercus intra cippos qui fecerit... Se trata no sólo de la tumba, sino de todo el área funeraria.

(7) Así lo vemos claramente especificado en:

- ILS,8289 (Roma): Appia Severina hizo un monumento funerario para su madre loco empto quo Tiburtini (cipos de piedra tiburtina) positi quattuor demonstrant (siguen las medidas del acotado funerario).

- ILS,8350 (Tibur)Hunc locum uti me viva determinaui cum ascensu gradum VII et cippis inscriptis VIIcollig(it) in circuitu p.CCCXXX... Corresponde a un acotado definido por siete cipos con referencia epigráfica.

- CIL,XIV,2467 (Castrimoenium):este epígrafe consiste precisamente en un cipo ubicado en el lugar que constituyó la concesión honorífica de un locus sepulturae, mediante el preceptivo decreto decurional,cuyo contenido se especifica en CIL,XIV,2466. 
otros menesteres (Dig., 47, 21, 1-3). Cuatro cipos acotando un área sepulcral son mencionados en:

- CIL, II, 1367 (Carissa Aurelia): un tal L. Postumius Silo costeó a sus expensas cuatro cipos para que quedara bien definida y libre de violaciones la tumba de su difunto amigo L. Fabius Severus (cippos sua impensa IIII d(edit) d(edicauit).

La utilización de tales cipos queda confirmada, por ejemplo, en la epigrafía funeraria de Bolonia, bien estudiada en el tema concreto de los espacios con medidas sepulcrales. Se constata (Donati, 1965, 90) la existencia de varios ejemplares de cipos con idénticas dimensiones, muy posiblemente fijados en diversos puntos de una misma área para delimitarla mejor.Tales cipos marcarían el entorno de un complejo funerario en cuyo centro se erigiría un monumento, ara, túmulo y el epitafio con el nombre del difunto. Dall'Olio (1922, 155), a su vez, señala en la colección boloñesa cipos dobles o triples, repitiéndose en varios casos la inscripción funeraria, y en otros simplemente la mera indicación de las medidas del área sepulcral. Menciona $(1922,152)$ cipos dobles que son exactamente copia uno del otro, con idénticos materiales, ornamentación, indicaciones de medidas, tipos de escritura, dimensiones, es decir, surgidos del mismo taller y destinados a ser emplazados en los costados del mismo monumento sepulcral. En uno de los ejemplos aportados tenemos sendos cipos, uno de los cuales señala primero la medida lateral del acotado funerario y luego la frontal y el otro, a la inversa, especifica primero la frontal, y luego la lateral, de lo que se desprende que ambos debieron ser emplazados respectivamente a un flanco y en la parte frontal del monumento, como sería el uso común.

Tales cipos irían, pues, ubicados en los lados tanto in fronte como in agro del área funeraria. Si la lápida erigida sobre la frons que daba a la vía permitía al viandante conocer los datos personales de los allí enterrados, y las dimensiones del espacio funerario, los cipos ubicados in agro marcarían los límites del terreno sepulcral, y en aquéllos casos en que se repetía el texto del epitafio situado fronte, el uso afirmaba la posesión del área comprendida en los confines indicados por tales cipos terminales.

Así lo vemos, por ejemplo, en uno de los casos recogidos por Dall'Olio (1922, 152), dos cipos gemelos que indican la misma superficie con la fórmula q.q.v.p. (quoquoversuspedes), y que conjetura que debían ser dos cipos laterales pertenecientes a la tumba de la familia 
Alennia, cuyo cipo principal, portando nombres y bustos de los difuntos, iría situado en la fachada del monumento (Donati, 1965, 93 s.). Otro ejemplo significativo, en este caso correspondiente a Roma, que confirma la ubicación de tales cipos en los confines del espacio funerario, nos lo suministra ILS, 8317, con este texto: Hic lofcus si]ve ager L. Rupili L.fSer.Magni est In fr.p.XX in agr.p. XXX. Se trata de dos cipos iguales, encontrados junto a la Via Flaminia, a veinte piés uno del otro exactamente.Veinte piés es también la medida in fronte, por lo que tales cipos irían ubicados en las esquinas del área sepulcral, en los extremos de su frons.

Un caso hispano de tal índole lo tenemos probablemente en nuestros nn. 25/26 (Astigi). Ambas inscripciones repiten los datos personales del difunto y las dimensiones del espacio sepulcral (12 piés in fronte y 10 piés in agro). Serían cipos terminales ubicados en diferentes confines para acotar la tumba del liberto L. Nonius Faustus en una necrópolis suburbana. Los dos epígrafes presentan igual forma (arco de medio punto, como es frecuente en los cipos), la misma clase de piedra y medidas similares, no idénticas. El texto tampoco ofrece la misma disposición en ambos casos, variando asimismo el tipo de letra.Quizás uno de los cipos fue emplazado en el área sepulcral algún tiempo después del otro (principios y mediados del s.I d.C.), quizás al estimarse conveniente por alguna circunstancia señalar aún mejor las medidas y límites del terreno funerario.

En 22 de las inscripciones que recoge Dall'Olio en su recopilación boloñesa $(1922,151)$ están señaladas las medidas del área funeraria al pié del correspondiente epitafio. En otras 35 solamente aparece la indicación de las medidas, por lo que podemos pensar que se trata de cipos simplemente terminales, de los que tenemos algunos ejemplos hispanos:

— n. 4 (Alcaudete).Debe ser un simple cipo terminal para indicar un área sepulcral cuadrada de 25 piés de lado, unos $56,25 \mathrm{~ms}^{2}$, pues no hay inscritos nombres ni fórmulas epigráficas funerarias.

- n. 92 (Castro del Río):consta solamente la referencia l(ocus) in fronte p(edes) CCXXV et in agro p(edes) $C L$.

En Bolonia, pues, además de incluirse las dimensiones en el preceptivo epitafio, se repetían tales datos espaciales en varios cipos que servían para delimitar cada terreno sepulcral. En el caso de Hispania, sin embargo, la mayoría de las indicaciones de medidas de acotados funerarios van incluidas en los mismos epitafios, siendo más escasos 
los simples cipos terminales. Quizás se usaron por economía cipos de piedra anepígrafos $\left(^{8}\right)$, considerándose supérfluo pagar un trabajo epigráfico simplemente "repetitivo", o hitos de madera. O bien los espacios funerarios correspondientes quedaban suficientemente acotados por muretes, paredes u otros elementos naturales o artificiales, de los que a veces se hace mención epigráfica, y cuya existencia hacía innecesaria la ubicación de cipos terminales, que siempre supondrían un gasto adicional a los muchos que entrañaba una tumba.

Además de por los cipos terminales, las fronteras de un espacio de uso funerario podían quedar visiblemente aclaradas por elementos naturales o artificiales, cuya función delimitadora es específicamente mencionada en los epígrafes, sobre todo por tratarse de termini que, a diferencia de los cipos de piedra, difícilmente podían sufrir modificaciones o ser trasladados de lugar. Sobre tales límites en general hace algunas observaciones el estatuto colonial de Urso (cap. 78). Podemos considerar los siguientes:

a) Muretes/Balaustradas:

- CIL, II, 1716 (Tucciy.monumentum et saepta.

- ILS, 8349 (Roma):fecit munimentum a solo cum agello concluso...habet autem agellus conclusus...

- ILS, 8335 (Roma):et hic locus macereola elusus ad familiam Messianam et Clodianam pertinet.

- ILS, 8338 (prope Minturnae) : huius monimenti ius que maceria clusum est cum taberna et cenacul. hered. non sequetur, neque intra maceria humari quemquam licet.

— ILS, 8345 (Roma):Huic monumento cedit hortus cum aedificio maceria elusus in fronte $p$...

- ILS, 8346 (Ostia):Huic monimento cedit siccanum totum hortorum cum piscina sua. In fronte $p$. CCLXXXX in agro comprensa maceria colligit iugera $25 / 12$ (in agro el locus alcanzaría 240 piés). En la extension in agro se incluye la que ocupa la cerca que rodea el acotado funerario.

$\left(^{8}\right)$ DALl'Olio (1922, 156) señala en la colección boloñesa tres cipos sin texto,hallados entre otros similares,pero con inscripciones,procedentes de la misma necrópolis.Quizás fueron incorporados a las áreas funerarias sin epígrafes,siendo inscritos "in situ" posteriormente, una vez erigidos los monumentos sepulcrales. 
- ILS, 8332 (Vicetia/cipo):/.s...m f.p. XXX ret.p.LX circumitus maceriae sesquipedes. Se ha especificado también la anchura de la cerca correspondiente, un pié y medio (unos 45 eins.).

b) PariesIParedes (cercados, vallas):

- CIL, II, 3960 (Puig de Cebolla): locum uti est concameratum $<$ cum> parietib(us) balneis hortis monumentum construxerunt.

- ILER, 3579 (Emerita):secundo pariete p(edes) VII) in a(gro)p(edes) $X$. La medida in fronte está aquí indicada con referencia al muro que ceñía la parte frontal del acotado funerario.

- Vaiverde y Perales, Historia de la villa de Baena, 1903, 48 s., fig.14:a pariete $p$ (edum) XEsta pared fijaría la separación con otra sepultura o sería limite de la finca.En todo caso serviría para delimitar la tumba.

— ILS, 8266 (Roma):m fron(te) p(edes) XXXVII, bersur. (versura) sinister. $p . X L V$, in agro paries long. $p . L V$.

c) Vias:

- CIL, II, 5919 (Ubeda):ex hoc loco usque ad vias publicas monimenti locus est. Sería un cruce de vías, por indicarse en plural.

— ILS, 7290 (Brixia) :Haec loca sunt lanar iorum... quae faciunt in agro p.C ad viam p.LV.

- ILS, 6746 (Vico Odalengo):T.Lollius...positus propter viam ut dicant praeterientes Lolli ave.

— ILS, 2466 (Castrimoenium):...locum...latum a via publica in agrum p(edes) $X$...

- ILS, 8327 (Roma, Via Ardeatina):In frote (sic) pedesp.m.XVI in latus pedes XVI item in latus in via Ardiatina respiciente longu pedes p.m. XXIIII et latu pedes $X$.

d) Corrientes de agua:

- CIL, XIV, 2466 (Castrimoenium):...locum...long(um) p(edes) LXVII ad rivom aquae Albanae...

— ILS, 8324 (Iader):Latum pedes XX, longum ab unda ad maceriam.

e) Fossae:

— CIL, XI, 8010 (Fulginiae)|infr.p. XV in ag. adfoss. 
- ILS, 8004 (Praglia):Hic locus patet in front(e) p(edes) XX et a mediafos (sa) in[ t/ro vers (us) p(edes) $X X V$...

También se constatan alteraciones en las extensiones de las áreas sepulcrales, lo que podía ocurrir si el terreno en que estaban emplazadas cambiaba de manos por venta o cesión, o si se consideraba necesario ampliar el acotado funerario inicialmente previsto, para atender más necesidades funerarias. En una de las inscripciones boloñesas (CIL, XI, 6839) vemos cómo el lado de un área funeraria fue ampliado de $20 \mathrm{a}$ 25 piés. La posible ampliación era, desde luego, más factible en fundi rurales, donde los terrenos sepulcrales estaban menos constreñidos que en el abigarrado, y más caro, suelo de las necrópolis suburbanas. Así, en el cipo de Castro del Río (n. 92) observamos cómo las cuatro últimas cifras del numeral CCXXV (pedes in fronte) están esculpidas en un plano inferior al resto de los caracteres del renglón.El texto fue ahí posiblemente cambiado tras la primera ejecución para escribir un nuevo numeral, quizás al aumentar las medidas del locus funerario original.E idéntica corrección debió hacerse en el numeral con la cifra de pedes in agro del tercer renglón, que quedó definitivamente en CL $\left({ }^{9}\right)$. La reutilización de cipos, ajustando sus datos a las nuevas medidas de los espacios acotados por ellos, sería uso común, bastaba actualizar las cifras tras borrar previamente las anteriores.

Otra posibilidad que podía darse consistía en reservar un área para usos funerarios, quizás futuros, pero sin precisar por el momento las medidas definitivas del acotado sepulcral. Así lo vemos en el n. 30 (Baeza), epígrafe que un tal L.Postumius dedica a su hermano e hija, incluyendo el texto las expresiones in fronte e in agro, pero dejando vacíos los espacios de las cifras correspondientes para añadirlos más tarde (cfr. CIL, XI, 7887).

Como indicamos supra, los epígrafes funerarios suelen adoptar con frecuencia la forma de estelas terminadas en arcos de medio punto. Es la forma típica de los simples mojones terminales anepígrafos, los cuales influyen formalmente, tanto en aquéllos cipos que incluyen sólo

(9) El cipo de Castro del Río,que indica un acotado de amplias dimensiones,poco frecuentes entre los espacios funerarios,pudo corresponder a la necrópolis particular de una villa rústica,donde se enterraron muchos individuos (esclavos, trabajadores libres), o bien donde hubo algunas sepulturas, pero con una gran extensión de horti circundantes bien definidos (R. Neila, 1983,192). 
la amplitud en piés del espacio sepulcral (locus pedum tot), como en los epitafios que, aportando las medidas de los acotados sepulcrales, además de los datos personales de los difuntos, sirven asimismo de hitos delimitadores. Del primer caso tenemos ejemplos en los nn. 66, 85 y 92, y del segundo en los nn. 18, 19, 25, 26, 69, 73.

\section{EXTENSION DE LOS ACOTADOS FUNERARIOS.}

Con relación a este punto observamos los siguientes hechos:

a) Gran variedad en las medidas tanto in fronte como in agro. Comparemos varios lugares que proporcionan información al respecto:

- Para el caso de Roma, más de 1500 inscripciones (tanto tituli funerarios como cipos delimitadores de acotados sepulcrales) suministran información sobre las medidas de los mismos. El tamaño de los espacios sepulcrales varía de modo considerable, desde pocos piés cuadrados a varios miles (Eck, 1987, 63).

Entre las medidas conservadas, las cantidades in fronte fluctúan entre medio y varios cientos de piés. Unas veces las medidas corresponden a mausoleos completos e individuales. Otras veces, sobre todo cuando se trata de bajas cantidades, posiblemente estamos ante tumbas incluidas dentro de un área sepulcral más grande, o se refieren a pequeños monumentos sepulcrales. Sin embargo, la mayor cantidad de las indicaciones pertenece originalmente a mausoleos unidos a un área sepulcral delimitada por muros con una construcción contenida en ella (Eck, 1987, 63).

De los 1451 casos analizados, 939 corresponden a la escala entre 10 y 20 piés in fronte, lo que supone más de dos tercios de todas las tumbas incluidas en tal categoría, por tanto las pequeñas dimensiones, como se constata, probablemente no se refieren en su mayoría a mausoleos. Además, dentro del margen de 10 a 20 piés, 624 textos aportan medidas entre 10-14 piés in fronte, y de ellos 402 indican 12 piés. Eck $(1987,64)$ concluye que debió existir una especie de tamaño "standard" de mausoleo, que osciló entre 10-14 piés in fronte, con particular abundancia de los 12 piés. Con respecto a la superficie total de los acotados funerarios romanos, Eck (1987, 63, n. 12), tomando como base la información del CIL VI, establece la siguiente clasificación:

— de 2 1/4-100 piés cuadrados: 378 ejemplos. 
— de 101-200 p.c.: 445 ej.

— de 201-400 p.c.: 371 ej.

— de 401-1000 p.c.:90 ej.

— de 1001-250.000 p.c.: 29 ej.

La gran mayoría de los espacios sepulcrales en la Urbs se sitúa aproximadamente entre 100-400 piés cuadrados, en suma más del $62 \%$ del total.

- En Ostia (Cébeillac, 1971,104) el mayor porcentaje de epígrafes con indicación de medidas de acotados funerarios se concentra en la banda de $20 / 30$ piés in fronte (37\%) e in agro (46\%); la siguiente concentración se registra en la escala de $10 / 20$ piés in fronte $(31 \%)$ e in agro (20\%), luego en la de 30/40 piés in fronte (13\%) e in agro $(18 \%)$. Los porcentajes más bajos los vemos en los dos extremos de la escala de dimensiones, las menores de 10 piés in fronte (13\%) e agro (9\%), y las superiores a los 40 piés in fronte (6\%) e agro (7\%).

Respecto a las superficies de los acotados, la escala se presenta así:

- la mayor densidad se da en la banda 500/600 piés cuadrados (13\%).

- luego siguen los espacios de $100 / 200$ p.c. $(12 \%)$.

- $\quad$ espacios $10 / 100,200 / 300,300 / 400$ p.c. (10\% cada grupo).

- espacios 600/700, 700/800 (9\%).

Los porcentajes más bajos corresponden a los acotados más pequeños, menos de 10 p.c. (1\%), y a los más extensos, $800-900$ p.c. (4\%), 900/1000 p.c. (6\%), más de 1000 p.c. (7\%).

- Para el caso de Bolonia (Donati, 1965, 95 s.) los mayores porcentajes de epígrafes con indicación de medidas de acotados funerarios se concentran en la banda de $10 / 20$ y $20 / 30$ piés in fronte, y $10 / 20$ y $20 /$ $/ 30$ piés in agro. Siguen en la escala los espacios inferiores a 10 piés in fronte y 10 in agro, siendo ya mucho más escasos los acotados con medidas entre 30/40, 40//50 y superiores a 50/100 piés tanto fronte como in agro. El lote "standard" en Bolonia, por tanto, estaba en 10/ 130 piés in fronte e in agro, siendo especialmente abundantes las medidas entre $12 / 20$ piés in fronte e agro, con predominio de los 16 y 20 piés en uno y otro lado. Por lo que respecta a la extensión de los espacios sepulcrales, basculan entre una superficie mínima de 14 piés cuadrados a una máxima de 5.000 piés cuadrados (CIL, XI, 6907), registrándose una acusada gradación intermedia. Entre los acotados funerarios de mediana extensión la cifra de 400 piés cuadrados es la más documentada (Donati, 1965, 91). 
- Para la necrópolis de Pian di Brezzo, en Sarsina, se ha sugerido (Ortalli, 1987, 162) que el terreno funerario estuvo subdividido en lotes sepulcrales de 18/20 piés in fronte.

- En la necrópolis de Colombara-Fondo Urbanetti (Aquileia) se observan espacios sepulcrales de $16 \times 16,16 \times 20,16 \times 25,16 \times 28,22 \times 22$ y $24 \times 16$ piés, predominando una medida "standard" de 16x16 piés, lo que es indicio de una precedente parcelación (Reusser, 1987, 244). Los epígrafes de Aquileia con medidas de acotados funerarios (350 ej.) ofrecen algunas sugestivas indicaciones:

- algo más de la mitad de todos los espacios tienen una extensión frontal de 16 piés.

— un $40 \%$ de los complejos funerarios miden $16 \times 16$ o 16x32 piés.

- entre las restantes indicaciones están 10, 20, 30, 40, 50, 60 piés (pero sobre todo 20 y 30 piés) como las más frecuentes.

- En Salona los espacios funerarios pueden ser de hasta $20 \mathrm{~ms}$. de largo, aunque generalmente no eran muy grandes, raramente rebasan los 50 piés y están situados con su lado largo a la calle (Cambi, 1987, 257).

Para el caso de Hispania podemos observar (Cuadro I) que la mayor cantidad de acotados de uso funerario con indicación de sus dimensiones se registra en la banda de $10 / 20$ piés in fronte y 10/20 piés in agro. Siguen en la escala, pero muy por debajo, las medidas entre 20/30 y 30/40 piés in fronte y 20/30 y $1 / 10$ piés in agro. Medidas superiores a 40 piés in fronte o in agro son muy escasas, constituyendo excepción las que superan los 100 piés en uno u otro lado. El acotado funerario "standard" en Hispania tiene, por tanto, entre 10/20 piés in fronte (de 3 a $6 \mathrm{~ms}$.) y $8 / 20$ piés in agro (de 2,40 a $6 \mathrm{~ms}$.), siendo predominantes las medidas de 12 y 15 piés in fronte $(3,60-4,50 \mathrm{~ms}$.), y 10,15 y 20 piés in agro (3-4, 50-6 ms.). Es, por tanto, algo superior al lote "standard" de Roma, que oscila entre 10/14 piés in fronte, similar al de Bolonia (10/30 piés in fronte e in agro) o Aquileia (16x16 piés), pero inferior al de Ostia, donde el porcentaje predominante oscila entre $20 / 30$ piés in fronte e in agro, y al de Sarsina (18/20 piés in fronte). En todo caso parece evidente la mayor escasez de suelo funerario en Roma, lo que repercutiría en más altos costes del terreno sepulcral.

Por lo que respecta a las superficies de los lotes funerarios hispanos (Cuadro II), sobre un total de sesenta casos analizados, en los que se han conservado las dos dimensiones in fronte!in agro, podemos extraer las siguientes conclusiones: 
CUADRO I

MEDIDAS DE LOS ESPACIOS FUNERARIOS HISPANOS

\begin{tabular}{|llll|}
\hline Pedes in fronte & NQ de casos & Pedes in agro & NQ de casos \\
\hline VII & 1 & I & 1 \\
VIH (=2, 40 ms.) & 2 & VII & 2 \\
IX & 1 & VIII & 5 \\
X (=3 ms.) & 4 & IX \\
XI & 3 & X & 3 \\
XII (= 3, 60ms.) & 29 & XI & 14 \\
XIV & 4 & XII & 1 \\
XV & 12 & XIV & 6 \\
XVI & 3 & XV \\
XVIII & 3 & XVI & 3 \\
XIX & 1 & XX & 7 \\
XX $(=6$ ms.) & 5 & XXIV & 1 \\
XXV & 3 & XXV & 7 \\
XXX & 2 & XXVII & 2 \\
XXXII & 1 & XXVIII & 1 \\
XXXIV & 1 & XXX & 1 \\
XXXV & 1 & XXXV & 1 \\
XXXVI & 1 & XXXVI & 1 \\
XXXX & 1 & XXXVIII & 2 \\
LXXXV & 1 & XXXX & 2 \\
CXX & 1 & Xc & 1 \\
CCXXV & 1 & CL & 1 \\
\hline
\end{tabular}

- Más de un tercio de los espacios sepulcrales (22 casos $=36,6 \%$ ) corresponden a la banda de 100/200 p.c. (=9/17,97 ms.cuadrados), siendo especialmente frecuentes los 120 p.c. ( $=10,8$ ms.cuadrados).

- Siguen en orden de importancia los acotados de extensión menor a 100 p.c. ( $=9$ ms. cuadrados), y los incluidos en la banda $200 / 300$ p.c. 


\section{CUADRO IL \\ SUPERFICIES DE LOS ESPACIOS FUNERARIOS EN HISPANIA.}

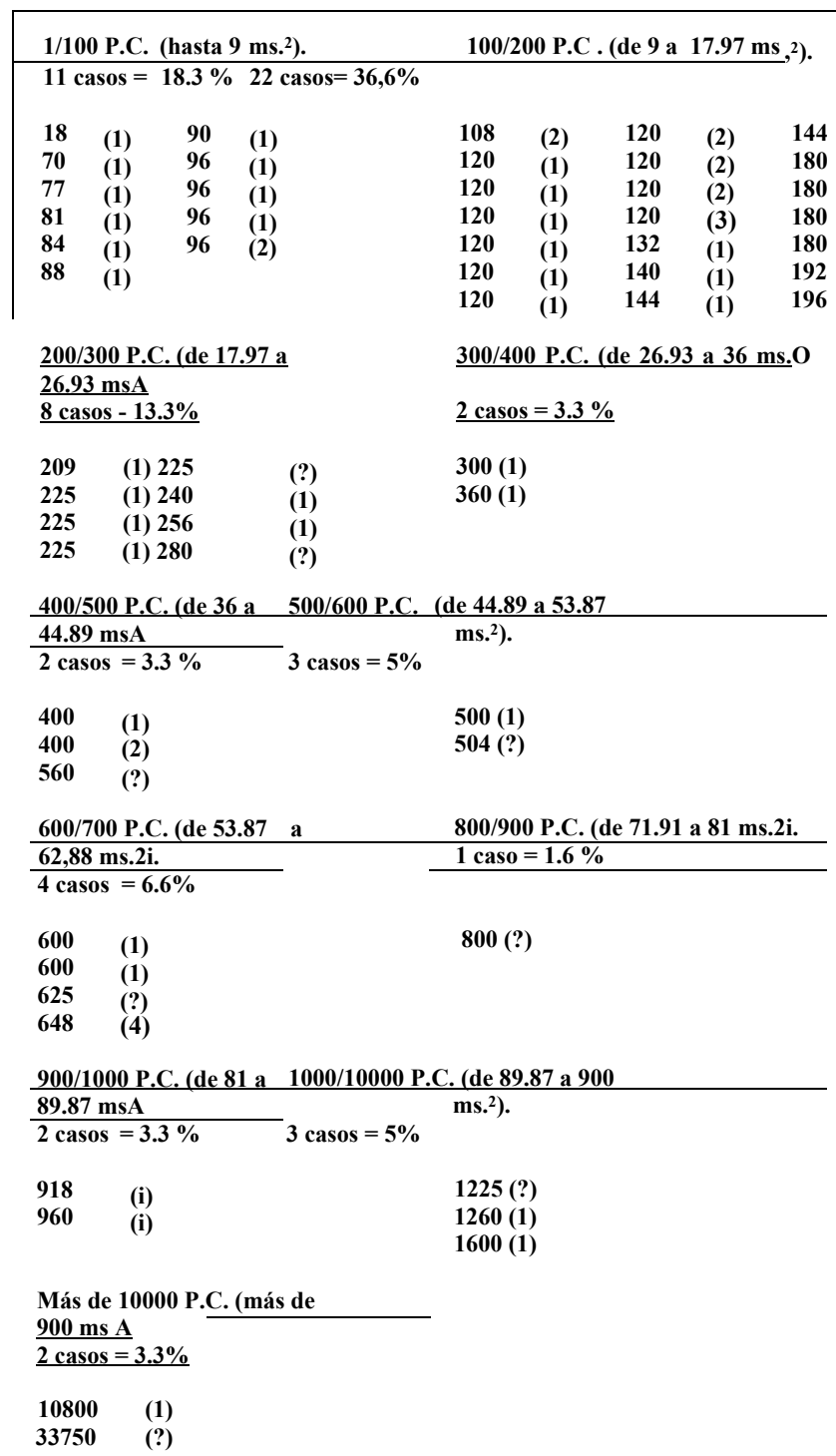

Observaciones:

-Cada una de las cifras distribuídas en los once apartados corresponde a la extensión en p.c. de un acotado funerario. Las cantidades entre paréntesis indican número de personas en él enterradas. 
(=17,97/26,93 ms.cuadrados), que suponen respectivamente el $18,3 \%$ (11) y el 13,3\% (8) de los casos considerados.

- Muy escasa representatividad tienen los terrenos funerarios con superficies entre $500 / 600$ p.c. $(=44,89 / 53,87$ ms.cuadrados) y $600 / 700$ p.c. $(=53,87 / 62,88$ ms.cuadrados).

- Excepcionales resultan los acotados funerarios superiores a los 1000 p.c. $(=89,87$ ms.cuadrados $)$ y 10000 p.c. (=900 ms.cuadrados).

Prácticamente la mitad $(49,90 \%)$ de los casos analizados son acotados funerarios entre 100/300 p.c., que constituye la superficie "standard" en Hispania (entre 9 y 26,93 ms. cuadrados). Fuera de esta banda los terrenos sepulcrales o no superan los 100 p.c. (menos de 9 ms.cuadrados), o bien constituyen ya casos excepcionales superiores a los 500,1000 e incluso 10000 p.c. En Roma la máxima concentración se registra en la banda $100 / 400$ p.c. (más del $62 \%$ del total), siendo escasa la representatividad por encima de los 1000 p.c. En Ostia, sin embargo, es la banda 500/600 p.c. la mejor ejemplificada, seguida de los 100/200 p.c. Los porcentajes más bajos se dan en los acotados inferiores a los 10 p.c., o en los que superan la cifra de los 800/1000 p.c. A su vez, en Bolonia la extensión media más documentada son los 400 p.c.

Ocasionalmente encontramos también en Hispania medidas tanto inferiores como superiores al promedio indicado:

$-30,32$ o 36 piés in fronte.

$-24,28,30,36$ o 38 piés in agro.

- 40 piés en ambas medidas en un epígrafe de Sabora (n. 70).

- 120 piés in fronte y posiblemente 90 piés agro en un epígrafe de Carthagonova (n. 31).

- En uno de Tucci (n. 85) se mencionan 85 piés sin indicar nada más; serían in fronte.

- 225 piés in fronte y 150 piés in agro encontramos en el cipo de Castro del Río (n. 92), que señalaría una parcela funeraria de dimensiones poco frecuentes.

Acotados funerarios de extensión excepcional son mencionados por algunas fuentes literarias. Cicerón, por ejemplo, habla de la concesión de un locus sepulturae a un personaje importante, con una extension de 30 x 30 piés ( 900 piés cuadrados $=81$ ms.cuadrados) (Cic., Phil., IX, 7, 17). A su vez, Horacio, al describir el cementerio del Esquilino antes de las mejoras introducidas por Mecenas, alude a un cipo que marcaba un área de $1000 \times 300$ pedes $(300.000$ p.c. $=27.000$ 
ms. cuadrados, más de dos hectáreas y media) (Hör., Sat, I, 8, 12-13). Quince veces menor en cuanto a extensión es el ostentoso monumento sepulcral de Trimalción descrito por Petronio \{Satyr., 71), que tenía 100 X 200 piés (20.000 p.c. $=1800$ ms. cuadrados), una tumba, de todas formas, excesivamente grande para un sólo individuo, una exageración más del vanidoso y estrafalario liberto.

El acotado funerario al que correspondió el cipo de Castro del Río (n. 92), con medidas de 225 × 150 piés, da un total de 33.750 piés cuadrados, es decir, 3.037,50 ms. cuadrados, más de una yugada (=un rectángulo de 28.800 piés cuadrados), unas 25 áreas, la cuarta parte de una hectárea. Es una extensión muy inferior a la del acotado del Esquilino, y a la de otro conocido por un epígrafe de Roma que alcanzó las cuatro yugadas $\left({ }^{10}\right)$, pero superior al monumento de Trimalción, y a las áreas sepulcrales más amplias documentadas por los cipos boloñeses (Donad, 1965, 94), 359,86 y 449,86 ms. cuadrados $\left({ }^{\mathrm{n}}\right)$.

¿Cuál pudo ser la condición de estos espacios funerarios de dimensiones tan fuera de lo común? Según Purcell (1987, 38, n. 62), las atípicas medidas del acotado que Horacio señala en el Esquilino no corresponderían a un recinto individual, sino más bien a un cementerio público completo, dentro del cual se distinguirían secciones más pequeñas. Otra posibilidad es que en tales casos estemos ante un commune sepulchrum al estilo de los poseídos por los collegia funerarios (cfr. Cébeillac, 1971, 102 s.) (12), o que correspondieran a familias ricas,

${ }^{(10)}$ ILS,4998 (Roma) : locus sepulchri continet per cippos dispositos iuger(a) quattuor. Una yugada $=240 \times 120$ piés $=72 \times 36 \mathrm{~ms} .=2592$ ms.cuadrados $\times 4$ iugera $=10.368 \mathrm{~ms}$. cuadrados,unas 100 áreas $=$ cerca de 1 hectárea. Ante esta excepcional extensión de 10.368 ms.cuadrados para un acotado funerario la referencia de Horacio no parece,ciertamente,exagerada.

O CIL,XI,6906:4.000 p.c.;CIL,XI,6907:5.000 p.c.

(12) No faltan ejemplos de acotados funerarios con indicación de medidas que pertenecen a colegios de diversa índole,que pudieron adquirirlos bien por compra o donación:

- CIL,XI,6135 (Forum Sempronii): loe.sep.sodalicium fabr.tig. in fr.p. IIII in ag. p. $X X$.

-ILS,7947a (Aquileia): l(ocus) m(onumenti) sodalium. In f. p.XXX,in ag. p. XXV.

- ILS,7340 (Roma): sociorum... in fronte p.X in agro p.X.

- ILS,7290 (Brixia): Haec loca sunt lanariorum carminator, sodatici, quae faciunt in agro $p$. $C$ ad viam $p . L V$.

— ILS,7344 (Roma): d.m. sepulcrum cum solo et ollariis Anni Phylleiis et collegi Phylletianorum in fronte pedes $X X X X$ in agro pedes $X X X X$... 
que adquirieron terrenos tan grandes para sepultar a todos sus miembros de diversa condición, incluidos esclavos y libertos (cfr.Donati, 1965, 94; DairOlio, 1922, 154). El cipo de Castro del Río pudo corresponder, quizás, a la necrópolis particular de alguna gran villa rural. Tampoco cabe descartar que se tratase de un monumento funerario rodeado por una gran zona de respeto con horti, piscinas, etc. Trimalción ambicionaba algo muy diferente a la consuetudinaria tumba reducida y constreñida entre otras dentro de una necrópolis, un monumento sepulcral profusamente decorado en medio de un amplio espacio con árboles frutales y viñas. Pero sus gustos se alejan, desde luego, de la tónica normal que, respecto a la extensión de los acotados funerarios, se infiere de la generalidad de los datos conocidos.

b) Normalmente las medidas in fronte son superiores a las medidas in agro, seguramente para tener más fácil acceso al locus sepulturae a efectos de cuidados de la tumba y ceremonias funerarias, y mayor proyección sobre la vía para atraer la atención de los viandantes. A veces, como hemos visto, ambas cifras son idénticas, tratándose de parcelas cuadradas.

c) En algunas ciudades observamos cierta regularidad en las dimensiones de los acotados funerarios. Ya hemos visto cómo Eck señala para Roma un tamaño "standard" entre 10-14 piés in fronte, con peculiar abundancia de 12 piés, siendo los espacios sepulcrales entre 100-400 piés cuadrados los más abundantes. En Ostia (Böschung, 1987, 117) también se observa cierta regularización en los espacios sepulcrales.En Bolonia el promedio de extensión de los acotados funerarios lo estima Donati en unos 400 piés cuadrados, lo que señala una escala algo superior a la de Roma. En Sarsina los lotes sepulcrales tuvieron por término medio 18-20 piés in fronte, lo que supera también las cifras medias de la Urbs. Y en el caso de Aquileia, los 16 piés in fronte son la indicación más frecuente, constituyendo los espacios funerarios de $16 \times 16$ y $16 \times 32$ un cuarenta por ciento del total. Pero no siempre ha debido ser esa la tónica general. Meiggs $(1985,456)$ resalta, por ejemplo, cómo uno de los más llamativos rasgos de las necrópolis ostienses es la aparente ausencia de control público en su desarrollo. No hay un plan racional, por ejemplo, en Isola Sacra, donde vemos la

— ILS,4172 (Pola): dendrophoris Polensium C.Laecanius Theodorus... lo[cu]m cum sepultura dedit. In fr. p. XLII in ag. p. XLII. 
misma dispersión y desorganización de tumbas que se señala en la Sententia Senecionis (ILS, 8391). Pero para otras zonas de Isola Sacra, con tumbas dispuestas de forma organizada a ambos lados de una nueva vía, se ha sugerido la hipótesis de un racional y programado plan de desarrollo (Baldassare, 1987, 129, 136).

A su vez, en ciertas zonas de la necrópolis ubicada junto a la Via Triumphalis en Roma, que empezó a usarse no antes de mediados del s. I d. C., Steinby $(1987,88)$ destaca la gran densidad de tumbas en la zona más apreciada, la vecina a la citada vía, siendo cada espacio sepulcral muy reducido. El hecho de que las tumbas "a celia" fuesen construidas en el s. II en filas compactas, a breve distancia de tiempo y con medidas que parecen "standard", podría indicar también la existencia de una especie de plano regulador, con áreas funerarias de dimensiones similares. A su vez, el solar de uno de los enclaves sepulcrales de Sarsina, junto al río Savio, destaca por su precisión catastral. La predeterminación de cada lote funerario en espacios de 3 ms. de lado, dentro del terreno funerario donado por Horatius Balbus para uso de los ciudadanos menos pudientes (ILS, 7846), contribuyó a subdividirlo y organizado espacialmente de modo regular. Dicha zona, que constituyó el núcleo de un posterior complejo funerario, debió mostrar cierta pobreza y uniformidad en la tipología sepulcral, tanto por el "status" de los destinatarios, como por la reducida superficie modular de los lotes (Ortalli, 1987, 157).

Por lo que respecta a Hispania, la dispersión de los datos impide obtener series de extensiones para determinadas ciudades, pero cabe observar, por ejemplo, cómo en Astigi la mayoría de las inscripciones que portan dimensiones de las tumbas, procedentes de las necrópolis suburbanas de la colonia, indican medidas entre 12-15 piés in fronte y 10-15 piés in agro, en Emerita aparecen prioritariamente las cifras 1012 piés in fronte y 8-10 piés in agro, y en Tucci encontramos varios epígrafes con 10-15 piés in fronte.

Como puede verse, las medidas in fronte ofrecen bastante similitud. Tal regularidad podría interpretarse como resultado de ordenanzas municipales concernientes a la distribución y medidas de los espacios de uso funerario $\left({ }^{13}\right)$ y a su protección como loci religiosi. No se ha conservado ninguna disposición concreta al respecto en los estatutos

(13) Chic, G.-Martínez Ortega, M. E., "Inscripciones inéditas de Ecija (Sevilla)",Gades, XII,1984,400;S. ORdóÑEz,Colonia Augusta Firma Astigi, Sevilla, 1988,88.

Conimbriga, 30 (1991), 59-94 
municipales, pero la Lex Imitaría (cap. 79) establece partidas de dinero para la custodia publica de los monumentos funerarios, preocupación que pudo hacerse extensiva a la disposición espacial de las necrópolis. Cabe también resaltar que las tres ciudades hispanas indicadas son colonias, a las que se adjudicaron territoria que experimentaron replanteamientos sustanciales en la disposición de un suelo, que se atribuyó en razón del número de colonos acogidos. Es factible que en las colonias el ordenamiento catastral abarcara incluso los espacios reservados para usos funerarios, acordándose oficialmente ciertos módulos para los acotados sepulcrales acordes con la superficie destinada a servir de necrópolis públicas. Y las dimensiones de tales acotados funerarios guardarían cierta relación con la cantidad de suelo suburbano disponible para dichos fines, y el precio alcanzado por el mismo. Por el contrario, en municipios y otras comunidades sin un replanteamiento territorial de base, y sin posibilidades de regularizar la distribución de las propiedades de origen, ha podido existir más libertad en el planteamiento superficial de los espacios de uso funerario. A su vez, en las áreas rurales el espacio ha podido ser menos caro, lógicamente, que en las zonas suburbanas y los acotados por tanto de dimensiones superiores, al haber zonas de secano desechables para fines utilitarios.

\section{RELACION ACOTADOS FUNERARIOS INUMERÒ DE PERSONAS ENTERRADAS.}

Con respecto a este punto cabe observar la inexistencia de una relación proporcional entre la extensión de los acotados funerarios y el número de personas enterradas en ellos que son mencionadas en los correspondientes epitafios. La explicación de tal hecho puede estar, como indica Eck $(1987,63)$, en que las medidas indicadas epigráficamente corresponden unas veces a mausoleos completos e individuales, pero otras, sobre todo cuando se trata de cantidades bajas, posiblemente a tumbas incluidas dentro de un área sepulcral más vasta, o se refieren a pequeños monumentos funerarios. En los casos de manifiesta desproporción entre acotados funerarios muy extensos y pocas personas enterradas en ellos, cabe pensar igualmente que el área se reservaría aún a más enterramientos futuros.

Cuando observamos que en acotados funerarios de pequeñas dimensiones se entierran varias personas, el hecho puede ser indicio, 
bien de utilización del rito de incineración, que suponía obviamente menos necesidad de terreno para la tumba, o bien de carestía y consiguiente encarecimiento del suelo funerario, especialmente en las necrópolis suburbanas.

Para el caso de Bolonia, Donati $(1965,94)$ hace referencia a un acotado de 400 piés (CIL, XI, 6861), destinado por cuatro libertos a su patrono, medidas confirmadas por un cipo terminal perteneciente al mismo acotado. Otro ejemplo que aduce (1965, 92 s.) es el de la gens Lesuria (CIL, XI, 6876): tres copias de la misma estela, que indican cómo el sepulcro estaba destinado a siete miembros de la gens, cinco ya muertos al erigirse el sepulcro. Para acoger a esas siete personas se dispuso de un área muy exigüa de 16 piés cuadrados, insuficiente para inhumarlas, de lo cual se desprende que debieron ser incineradas. Esos 16 piés cuadrados son incluso escasos para las tres que se entierran en CIL, XI, 6858. Por el contrario, el sepulcro destinado a la gens Alennia (CIL, XI, 6925), compuesta por seis miembros (padres, tres hijos y una liberta) tenía un área de 256 piés cuadrados (16×16 piés). En los casos boleñeses analizados no se observa, desde luego, ninguna relación proporcional entre superficies de acotados funerarios y número de personas enterradas en ellos.

Por lo que respecta a Hispania, se percibe idéntica situación (cfr. Cuadro II). En la banda más representada, espacios entre 100/200 p.c., se han enterrado entre $1 / 3$ personas. Acotados de 120 p.c. han recibido lo mismo uno que dos o tres cuerpos. Lo normal es que se mencione una sola persona. Pero lo mismo ocurre en los espacios inferiores a 100 p.c., o en los comprendidos entre 200/300 p.c., que siguen en orden de importancia, donde vemos prácticamente en todos los casos un sólo cuerpo enterrado. Desconociendo el tipo de ritual funerario empleado (inhumación o incineración), y la disposición y amplitud del monumento sepulcral correspondiente, resulta difícil extraer conclusiones sobre el índice de aprovechamiento de los espacios funerarios. Así, mientras en un caso vemos cómo un acotado de 648 p.c. acoge cuatro personas, otras veces nos encontramos ante lotes de 600 p.c. con un sólo individuo enterrado. Una sola persona es también mencionada en terrenos de 918, 960, 1260, 1600 y 10800 p.c. Si comparamos este "índice de aprovechamiento" de los espacios sepulcrales hispanos con las observaciones hechas a propósito de Bolonia, parece evidente que en Hispania la "presión demográfica" ha repercutido con menos intensidad tanto en la disponibilidad de terreno funerario como en su coste. 


\section{ESPACIOS DE USO FUNERARIO Y NIVEL ECONOMICO.}

El incremento de la densidad demográfica en muchos centros urbanos pudo suponer, como ha destacado Purcell $(1987,33)$, una notable presión sobre el aprovechamiento que las comunidades podían obtener de la tierra suburbana para fines agrícolas o de otra índole. Ello supuso tanto dificultades crecientes para acometer los ritos funerarios en el espacio inmediato extra pomoerium, como un progresivo encarecimiento de ese suelo. Dado que el tema del enterramiento preocupaba en vida a todo romano, que aspiraba a tener al menos un lugar de sepultura digno, y si era posible un monumento en los emplazamientos privilegiados dentro de las necrópolis, el citado proceso implicaba ciertos problemas: dónde enterrar a la población servil y a los pobres libres más indigentes; y cómo atender las expectativas de ciudadanos libres y con medios económicos modestos a tener adecuadas disposiciones funerarias, difíciles de conseguir ante la escasez de suelo. Cierto control sobre el desarrollo de las zonas funerarias por parte de los poderes municipales, y la disposición de tierra pública en tales enclaves, bien puesta en venta a particulares, reservada para enterramiento de los más necesitados, o concedida gratuitamente como honor especial a personas eméritas, pudieron ser soluciones para atenuar al menos tales exigencias.

La respuesta a tales presiones fue la masiva inversión de recursos para adquirir lotes funerarios en las áreas suburbanas, y para costear tanto una arquitectura sepulcral, que asume moldes homogéneos a lo largo y ancho del Imperio, como un variado repertorio de usos funerarios. En su ilustrativo estudio Purcell $(1987,33)$ pone de relieve el incremento en época imperial de los dispendios funerarios. Las cifras medias para costes de tumbas en dicho período son 1000 HS en Africa y 2000 HS en Italia, los precios más altos son 20-80.000 HS en Africa y 100.000 HS y más en Italia (cfr. Duncan-Jones, 1982, 99-101, 166171, n. 244, 636). Dicho autor estima que el incremento de la riqueza privada en la sociedad romana podría explicar al menos parcialmente el fenómeno funerario $(1987,35)$.

Sin embargo, el tamaño de los espacios sepulcrales, y la propia disposición monumental de los mismos, no siempre guarda una estricta correspondencia con la jerarquía social y económica que se da en las ciudades. No hay necesariamente un tipo "standard" de acotado funerario que corresponda a gentes pertenecientes a los más altos niveles 
sociales (decuriones, magistrados municipales, seviri Augustales), y otro que deba relacionarse con los sectores plebeyos de la población local. En los acotados funerarios con indicación de medidas in fronte!in agro, cuadrados de diez y doce piés son los más comunes, pero hay otros muchos tamaños "standard", lo que sugiere que, aún tratándose de gentes con un relativamente bajo índice de gastos funerarios, las preferencias no eran uniformes, se estratificaban según las disponibilidades económicas, variando más intensamente entre los bajos niveles sociales que entre los altos (Purcell, 1987, 35, n. 44).

En Aquileia, por ejemplo, la relación entre superficies de las tumbas y estratificación social no abona ninguna idea de jerarquía (Reusser, 1987, 244). En los grandes y pequeños espacios y en aquéllos con los tamaños normalizados de $16 \times 16$ y $16 \times 32$ piés se constata una mezcla de diferentes capas sociales. Por el contrario, Cébeillac (1971, 102 s.), examinando las inscripciones ostienses con dimensiones de áreas funerarias, observa que los personajes más importantes de la ciudad, decuriones, magistrados, ricos libertos, seviri Augustales, adquirieron emplazamientos funerarios de superficie en general superior a las de los acotados correspondientes a gentes de una escala social inferior. Aunque dicha autora estima que fuera de Ostia los resultados de encuestas parecidas pueden arrojar resultados diferentes. Así, Donati $(1965,94)$ señala que, al menos en Bolonia, la relación entre monumento/estrato social no es significativa de la situación social de la ciudad.

Conviene también tener en cuenta que en Ostia, como en Aquileia, las superficies funerarias más grandes fueron a menudo propiedad común de colegios funerarios de libertos o esclavos (Cébeillac, 1971, 102 s.). Es factible que en aquellas localidades donde los terrenos para uso sepulcral escasearan o adquirieran altos precios, o donde la propiedad estuviera menos repartida, el recurso de los humildes a los colegios funerarios fuese más frecuente. Donati $(1965,94)$ estima que la escasa constatación de colegios funerarios en la epigrafía de Bolonia podría explicarse por el escaso desarrollo del latifundismo en la Emilia, donde sería más fácil poseer espacios para uso funerario.

En Hispania proliferaron mucho los colegios funerarios, en nada diferentes a los del resto del mundo romano en cuanto a organización y funcionamiento. Santero $(1978,92)$ señala su más frecuente aparición en ciudades de cierta importancia y una mayor concentración en la Bética. Este hecho puede guardar relación con la más fuerte romani- 
zación del área meridional hispana. Más difícil es percibir si cabe establecer relación entre tal fenómeno y el sistema de reparto de la propiedad, máxime cuando hoy parece evidente que la expansión del latifundismo antaño adjudicado a la Bética no lo fue tanto. De hecho muchas inscripciones hispanas con medidas sepulcrales corresponden a libertos/ /esclavos, que serían enterrados en el fundo o tumba familiar de su señor o, en el caso de libertos, en un acotado adquirido por sus propios medios.

Otro detalle que debe apreciarse es que la adquisición de un acotado funerario más o menos amplio no ha tenido necesariamente que estar en consonancia con las disponibilidades económicas, ha podido depender simplemente del rito funerario escogido. Como resalta Steinby $(1987,108)$ para el caso de la necrópolis romana de la Via Triumphalis, las aras son siempre asociadas a incineración, a diferencia de las estelas, que pueden constituir también la referencia de una tumba "a cappuccina" (inhumación), que no tiene por qué ser signo de pobreza. La elección entre incineración y sepultura en olla por una parte, e inhumación (con mayor amplitud y coste del área ocupada) por otra, no es cuestión económica, sino ritual, y el nivel de prestigio en tal caso no debe medirse por la extensión del acotado, sino por el monumento visible sobre la superficie.

Tampoco dentro de las necrópolis se establece siempre una repartición de sectores de acuerdo con las categorías sociales. La necrópolis de Isola Sacra, donde muchas tumbas de especial notoriedad monumental presentan sólo una inscripción en la fachada, que individualiza el grupo familiar al que pertenecen e indica las medidas del acotado funerario, fue frecuentada por gentes de origen libertino y modesta condición (Baldassare, 1987, 136 s.). En la necrópolis de ColombaraFondo Urbanetti (Aquileia), los espacios regularmente acotados corresponden a magistrados municipales y sus familiares, frecuentes beneficiarios de concesiones decurionales de un locus sepulturae, pero también a otros ciudadanos libres y libertos, todos aparecen mezclados, sin ningún indicio de jerarquía en las hileras de tumbas (Reusser, 1987, 244). Por el contrario, la necrópolis pompeyana de Porta Nocera no debió ser la considerada de mayor prestigio entre los miembros del ordo local, como lo prueba la escasez de concesiones honoríficas de suelo y funerales a expensas públicas y, por el contrario, la abundancia de tumbas de libertos. (D'Ambrosio-De Caro, 1987, 201).

En todo caso, lo que sí establecía categorías dentro de una necrópolis, al margen de consideraciones espaciales o monumentales, 
era la recepción del locus sepulturae por decisión decurional, honor apetecible por cuanto suponía disfrutar gratuitamente de un acotado procedente de la tierra pública disponible en las zonas suburbanas de uso funerario, donde los costes del terreno se encarecían más.

Por lo que concierne a Hispania contamos con un grupo de inscripciones (hemos catalogado cuarenta y una al respecto), que contienen referencias a "honores funerarios". Como se desprende de nuestro Cuadro III, la mayoría de tales epígrafes son de carácter honorífico, solamente en casos contados pueden considerarse estrictamente funerarios. Siempre se indica explícitamente la entidad municipal que ha otorgado tan apreciadas distinciones, que no es otra que el ordo decurional (decrevit, decreto decurionum), a veces asociado al populus local (nn. 4, 19). En ocasiones se indica el conjunto de la población local con el término colectivo (nn. 32, 33), o la institución municipal como tal (nn. 34 a 37), sin dejar de aludirse claramente al decreto decurional por el que se concedían tales distinciones. El carácter de homenaje público a las personas así distinguidas queda de manifiesto con la voz publice (nn. 7, 21). Nunca se indica en los epígrafes los méritos que hicieron a tales personas acreedoras de los "honores funerarios" con que las ciudades les distinguieron, tan sólo en una ocasión (n. 14) se señala genéricamente ob merita. No obstante, esta ausencia de detalles resulta normal en las inscripciones municipales que recogen distinciones honoríficas a magistrados, cargos sacerdotales o particulares eméritos.

Pensamos que esta clase de "honores funerarios", aunque concernían al ritual que rodeaba al momento de la muerte, al enterramiento y a la conservación de la memoria del difunto, hechos ante los que el romano estaba muy sensibilizado, eran concedidos en vida de la persona así homenajeada. Solamente en tres casos (nn. 30, 39, 40) se señala explícitamente que los honores fueron otorgados tras la muerte del recipiendiario (post mortem, huic defuncto). Pero resulta logico pensar que el locus sepulturae se otorgara en vida del destinatario del honor, para que este pudiera con tiempo, conociendo el lugar de su última morada, tomar las disposiciones pertinentes para preparar, como hizo Trimalción, su acotado y monumento funerarios. Otro dato curioso es que nunca se indican las medidas del locus sepulturae concedido honoríficamente, aunque se trataría por lo general de espacios con medidas "standard", dentro de la regulación municipal de las áreas funerarias a que hemos aludido. No habría, pues, diferencias de tamaño 
sustanciales en esta clase de loca sepulturae, que respondieran a cierta gradación honorífica.

Como se aprecia en nuestro Cuadro III, entre los "honores funerarios" el más frecuente era la concesión de un locus sepulturae, consta en casi todos los casos recopilados, lo cual indica obviamente que constituía el más apreciado, dada la carestía del suelo suburbano y el deseo de los notables locales de enterrarse en los espacios más privilegiados y ostentosos. Muy abundantes son también las referencias al pago de los costes del funeral con cargo al erario municipal (impensa funeris) y al permiso para pronunciar un elogio o laudatio (publica, según se hace constar explícitamente algunas veces) en honor de la persona distinguida, cuando ésta falleciera y tuviera lugar su ceremonia fúnebre. Como contribución a la perpetuación de su recuerdo, algo que jugaba un importante papel en el restringido horizonte social del microcosmos municipal, las concesiones anteriores iban acompañadas frecuentemente del permiso para erigir una statua en lugar público. Excepcionalmente se precisa que la statua es pedestre o ecuestre (nn. 9, 22). Lo normal era conceder una statua, aunque en Mellaria (n. 31) un flamen de la Bética fue distinguido con statuas equestres duas.

En menor escala están documentados en Hispania otros tipos de "honores funerarios". Como hemos visto, lo normal era que el ordo local otorgara graciosamente el estricto espacio de uso funerario, el locus sepulturae, y asumiera también los costes del funeral (impensa funeris), pero no los gastos de erección del monumento total o parcialmente. Sin embargo, excepcionalmente podía asumir tales costes, como probablemente ocurrió en Corduba (n. 25) con cierta concesión honorífica que, además de la impensa funeris y el locus sepulturae, abarcó igualmente lapides at extruen/dum monumentum. Lapides ad monimentum constituyeron, junto a la impensa funeris, las honras con que fue obsequiado en Urso un joven de diecinueve años de ilustre cuna local (n. 15). También en Lacilbula (n. 13) la concesión de "honores funerarios", además de locus sepulturae, impensa funeris, laudatio y statua, que solían constituir las distinciones más frecuentes, abarcó el monumentum funerario. Finalmente el catálogo de "honores funerarios" constatados en la epigrafía hispana se completa con aquéllos que únicamente están documentados de modo excepcional. Así en dos casos (nn. 23, 35), junto a la impensa funeris se especifica la concesión de exequiae que, aunque no se indique, debemos entender como públicas. Raras veces el honor consiste en cantidades de incienso (thurispondo...) 
para el ceremonial funerario (nn. 10, 16, 17), y una sola se otorga el clupeum (n. 9). En una ocasión (n. 41) el ordo decreta locus sepulturae, impensa funeris publica et omnes honores, expresión que abarcaría probablemente algunos de los ya señalados.

Un caso singular entre los "honores funerarios" documentados epigráficamente en Hispania lo constituyen CIL, II, 3251-3252. Un personaje de nombre C.Sempronius Celer, natural de Baesucci, fue homenajeado ampliamente tanto en su comunidad de origen, como en otras tres localidades también del conventus Carthaginiensis, Laminium, Tugia y Vivatia. En Baesucci los cives e incolae locales le distinguieron con statuas, costeadas obviamente ex aere coniato, mientras que el municipio, representado por el ordo decurional, le otorgó locus sepulturae, laudatio, impensa funeris, una statua y las correspondientes exsequiae. Cabe pensar, por tanto, que la ceremonia funeraria de Celer tuvo lugar en Baesucci (de hecho es la única de las cuatro ciudades que concedió las exsequiae públicas), y que fue allí, en el locus sepulturae que le donó la ciudad, donde fue enterrado. No obstante, los ordines decurionales, en vida de Celer, le concedieron cada uno algunos honores funerarios similares. En Laminium laudatio, además de statua, en Tugia y Vivatia locus sepulturae, laudatio e impensa funeris. Probablemente esta familia tuvo vinculaciones muy estrechas con aquellas comunidades, tanto por tener en todas ellas propiedades, como por haberlas beneficiado con iniciativas que desconocemos, a las cuales los respectivos ordines quisieron responder de una forma, digamos, "testimonial", concediendo un tipo de honor de especial aprecio social, como el locus sepulturae en Tugia o Vivatia, que no llegaría a ser utilizado. Lo mismo cabría decir de la laudatio o la impensa funeris en ciudades, como Laminium, Tugia o Vivatia, donde Celer no debió ser enterrado.

Pero también cabe la posibilidad de que en los loca sepulturae otorgados a este individuo en ciudades distintas a su patria chica, figuraran tras su muerte, como afectuoso recuerdo público a su memoria, sendos cenotáfios, y que incluso se celebraran ceremonias fúnebres en su honor costeadas con dinero municipal, con la correspondiente laudatio. Recordemos a tal efecto cómo algunas inscripciones con indicación de "honores funerarios" no proceden exactamente del lugar donde presumiblemente los homenajeados recibieron sepultura. A tal efecto podemos traer a colación nuestro n. 27. El epígrafe apareció en las cercanías de Almodovar del Río, solar de la antigua Carbula, pero hace referencia a un tal Asiaticus, que fue duunviro de Colonia Patri- 
cia Corduba, donde el ordo local le otorgó un locus sepulturae, además de impensa funeris y statua. Lo logico es que Asiaticus fuese enterrado en una de las necrópolis cordobesas, en el espacio funerario donado por la curia, lo cual constituía un honor, y no en su presumible fundus de la zona de Carbula, donde se halló la inscripción, que pudo corresponder a un cenotáfio erigido en su villa rural. Un caso similar lo tenemos probablemente en el n.28, un epígrafe encontrado en el término de Lucena, al sur de Córdoba, que menciona a L.Postumius Superstes, de 85 años, en cuyo favor el ordo de Colonia Patricia, donde había sido duunviro y pontífice, concedió locus sepulturae, laudatio, impensa funeris y statua. También aquí resulta factible pensar que dicha inscripción estuvo en un cenotáfio erigido en la villa rural que Postumius debió tener en el territorio de Cisimbrium, aunque él debió ser enterrado en una de las necrópolis cordobesas, aprovechando el locus sepulturae con que públicamente había sido distinguido como reconocimiento a sus servicios en el gobierno municipal.

¿Quiénes aparecen como beneficiarios de las concesiones de "honores funerarios"? Por lo pronto, hay predominio absoluto de libres, no consta ningún otorgamiento a libertos, aunque sí algún caso de hijo de liberto. Pero, en contra de lo que en principio pudiera esperarse, la mayoría de las veces se trata no de magistrados municipales o cargos sacerdotales locales o provinciales, sino simples particulares, algunos, incluso, abundantemente homenajeados en diferentes comunidades, como el ya citado Celer. Tales privati son mayoritariamente hombres, pero también encontramos varios ejemplos de mujeres que fueron reconocidas públicamente con tales distinciones. Cabe pensar que, aunque no se tratara de personas que revistieran cargos públicos, sí pertenecieron a las familias municipales notables, y acumularon ciertos méritos en pro de sus comunidades, que fueron reconocidos adecuadamente.

En ciertos casos la vinculación parece evidente. Así en Ugia (n. 16) un individuo, junto al locus sepulturae y honores afines, fue reconocido por el ordo con los ornamenta decurionales. Lo mismo vemos en Hispalis (n. 8), donde un tal Q. Iunius Venustus, posible joven (su padre asumió los gastos honoríficos), recibió locus sepulturae, funeris impensa y laudatio publica, así como los ornamenta decurionales. Tales símbolos externos de la dignidad decurional pudieron figurar, como era costumbre, en los respectivos monumentos funerarios.

En Asido (n. 10) C. Clodius Blattianus fue honrado con locus sepulturae, turis p(ondo) C (librae) y statua. A sus 18 años aún no 
había podido tener una efectiva proyección pública que le aportara méritos al servicio de la colectividad. Algo similar ocurrió en el caso de C. Aemilius Faustinus, de Urso (n. 15), quien con 19 años fue reconocido con locus sepulturae, impensa funeris, lapides ad monimentum $\mathrm{y}$, lo que resulta más significativo, los ornamenta inherentes a un cargo, el duunvirato, que por su edad aún no podía revestir. A su vez en Corduba un tal Heres (n. 25), de 12 años, quizás vinculado familiarmente a la importante familia de los Planii ( $\left.{ }^{14}\right)$, fue distinguido con impensa funeris, monumentum y posiblemente locus sepulturae. En ninguno de estos casos, obviamente, los ordines locales añadieron a tales concesiones el derecho a una laudatio, dado que tales jóvenes no habían tenido oportunidad de ocupar funciones municipales, haciéndose acreedores a unos méritos personales puestos al servicio de la ciudad, que era lo que a fin de cuentas constituía la sustancia de todo elogio público.

Al honrar así a tales jóvenes el objetivo principal de los ordines decurionales fue seguramente distinguir de modo elocuente a sus respectivas familias, que pertenecerían a las correspondientes oligarquías locales. Tal pudo ser el ya citado caso de Sempronius Celer, quien no parece llegara a desempeñar funciones municipales. Otro ejemplo elocuente es el n.26, donde vemos cómo el ordo de Colonia Patricia privilegió con locus sepulturae, funeris impensa y statua (mas no con laudatio) a T. Flavius Antoninus, hijo (o quizás hijastro) de un liberto imperial tabularius de la provincia Bética, a quien realmente los decuriones cordobeses desearían exaltar.

Aunque quizás no sea extensible a todas las ciudades lo que constata Castren $\left({ }^{15}\right)$ para el caso de Pompeya, donde el ordo solía pagar corrientemente los gastos de enterramiento de sus miembros, concediéndoles asimismo el locus sepulturae, sí tenemos varios casos hispanos donde los beneficiarios de los "honores funerarios" fueron miembros de la oligarquía decurional, que se distinguieron en el ejercicio de funciones públicas que les dieron un alto prestigio social, sancionado e incrementado con tales reconocimientos honoríficos. Esas personas desempeñaron el duunvirato, máxima dignidad política municipal (nn. 2, 22, 23, 24, 27, 28, 30, 38), la edilidad (nn. 22, 38), el

${ }^{14}$ ) R.C.KNAPP,"La Epigrafía y la Historia de la Córdoba romana”, Anuario de Filología, 6,1980,70 s.

(15) P. Castren, Ordo Populusque Pompeianus. Polity and Society in Roman Pompeii, Roma,1975,61. 
flaminado o el pontificado municipal (nn. 2, 28, 38) e incluso el flaminado provincial (nn. 2,31). También tenemos algunos ejemplos de flaminicas municipales $(\mathrm{nn} .1,24)$ y provinciales (n. 1). Incluso en ciertos casos (nn. 24, 33) la concesión honorífica se extiende a más de un miembro de una gens local (la Papiria en Baedro, la Acilia en Sacili Martiales).

Cabe señalar finalmente que, como suele ser frecuente cuando los ordines municipales decretan honores públicos en favor de determinados ciudadanos, incluso con cargo al erario municipal \{impensa funeris, statua, etc.), también en el caso de los "honores funerarios" el gasto podía ser asumido \{honore usus, honore accepto...impensam remiserunt, impensa remissa, etc.) por los familiares del homenajeado, librando al tesoro local de tal dispendio, modo de actuar que constituía a ojos de la colectividad municipal una munificente actuación que incrementaba los méritos de la gens. Así vemos actuar a padres (nn. $5,6,8,14,20,21,26$ ), hijos (nn. 30, 32), esposos (n. 5), esposas (nn. 12,31 ) y hermanos (n. 14) de los homenajeados.

Los casos hispanos epigráficamente documentados de concesiones de locus sepulturae y otros "honores funerarios" por parte de los ordines decurionales corresponden mayoritariamente a la Bética (34 personas), siguiendo la parte E.y SE. de la Tarraconense ( 8 menciones) y la Lusitania ( 2 menciones). Esta clase de honores se atestigua prioritariamente en las zonas más romanizadas, con representatividad especial en aquellas localidades que disfrutaron del estatuto colonial o municipal.

No todos los oligarcas municipales o personas con medios económicos han debido enterrarse necesariamente en las necrópolis suburbanas, donde el terreno funerario podía encarecerse. Han podido hacerlo en sus propios fundos, aunque el deseo de ostentación y memoria perenne hacía apetecible enterrarse junto a las vías de acceso a las ciudades, lo que motivaba la demanda de espacios de uso funerario acreditada por las referencias epigráficas, hecho que contribuiría obviamente a su encarecimiento. Que las ciudades concedieran el $l o-$ cus sepulturae como una alta distinción a ciudadanos eméritos, siendo necesario para ello un dictamen favorable de la curia local, expresado mediante decreto, al margen de las connotaciones ostentatorias del tema, indica también que se apreciaba el honor por lo que significaba económicamente, dada la carestía del espacio funerario suburbano.

El coste del terreno funerario ha debido variar posiblemente según las partes del Imperio. A partir de las medidas de los acotados sepulcra- 
les, cabe inferir que las áreas funerarias hispanas tienen por término medio dimensiones superiores a las constatadas en las inscripciones de Roma-Ostia que recogen A.M.Rossi y W.Eck. De donde podría desprenderse que en estas ciudades, con una concentración urbana elevada, el coste del terreno sepulcral debía ser muy alto, repercutiendo ello en el menor promedio dimensional de los espacios de uso funerario ${ }^{(16)}$.

Los precios de tales lotes variaban grandemente, pero eran generalmente muy altos, signo evidente de la presión que recaía sobre el espacio suburbano. Une esclavo de Agripa, por ejemplo, pagó $120 \mathrm{HS}$ por un lote de $11 / 2$ pedes cuadrados (CIL, VI, 21866); un esclavo de Livia compró un lote de $6 \times 31 / 2$ pedes por 180 HS (CIL, VI, 25260); en CIL, VI, 27619, un acotado de 12x18 pedes y la tumba correspondiente valen $1500 \mathrm{HS}$; en CIL, VI, 33846, se abonan $16.000 \mathrm{HS}$ por un lote de $12 \times 12$ pedes y la tumba; y en CIL, VI, 23791, un espacio de $5 \times 4$ pedes cuesta $20 \mathrm{HS}$. A Trimalción su ostentoso recinto funerario le habría costado sobre unos cien mil sestercios en las zonas más baratas de la periferia urbana. Pero tumbas más amplias in fronte/in agro que la del vanidoso liberto están atestiguadas epigráficamente. Los medios financieros de quienes eran enterrados en tales cementerios parecen haber variado mucho (Purcell, 1987, 38).

Aunque no tenemos datos explícitos de precios para las provincias ibéricas, en las ciudades hispanas el coste del terreno sepulcral no debió ser tan alto, quizás por disponibilidades territoriales mayores, no sólo de suelo privado, sino también público, dadas las frecuentes concesiones de locus sepulturae constatadas epigráficamente. Debían estár más cercanos a los de Africa ya indicados.

${ }^{(16)}$ Un dato significativo al respecto nos lo señala S.MrozeK (Prix et rémunération dans VOccident Romain,Gdansk, 1975,39 s.):en época de César el alquiler de una vivienda en Roma era cuatro veces más elevado que en los municipios de Italia. Como resalta P.GARNSEY ("Urban property investment", en M.I.Finley (ed.), Studies in Roman Property, Cambridge, 1976,123 ss.),la propiedad urbana (y,añadiríamos,suburbana),aunque menos atendida por los estudiosos que la rural,fue objeto de activa especulación. Las fuentes literarias parecen indicar que la propiedad urbana aportaba un alto nivel de renta,aunque también era más vulnerable a riesgos y a perder valor en el mercado. La preocupación de los estatutos municipales (cfrLex Urs., cap.75; Lex Mal, cap.62; Lex Tar., 32 ss.) por la demolición y desteje de los edificios ruinosos podría indicar que acciones incontroladas de tal clase podían acometerse por los particulares para hacer de ello una rentable empresa (venta de materiales,especulación para revalorizar los solares).

Conimbriga, 30 (1991), 59-94 
Finalmente, un "indicador economico" de los costes de espacios funerarios podrían ser las multas sepulcrales documentadas principalmente en Italia, cuyas cifras, según Rossi $(1975,154-157)$, pueden guardar relación con las dimensiones y probable precio del área sepulcral. En los casos de Roma y Ostia, que constituyen el objeto de su estudio, las multas oscilan entre 10.000/50.000 sestercios. Cuando se especifican multas entre 10/20.000 sestercios las medidas de las tumbas no superan jamás los 12 piés de lado. Las medidas que corresponden a una sanción de 20.000 sestercios oscilan entre 8/12 piés de lado. El área sepulcral menos extensa, $7 \times 7$ piés, tiene significativamente la multa más baja, 10.000 sestercios (CIL, VI, 29916). Según Rossi (1975,158), probablemente la regla general con respecto a las multas sepulcrales fue que su importe superase el coste del área sepulcral $\left({ }^{17}\right)$. Si guardásemos la proporción importe multa sepulcral/extensión del área funeraria que observamos en Italia, tendríamos que a las áreas funerarias hispanas, que oscilan por término medio entre $12-20$ piés in fronte y 8-20 piés in agro, les corresponderían multas entre 20/50.000 sestercios.

\section{BIBLIOGRAFIA}

Baldassare, I., "La necropoli dell'Isola Sacra (Porto)", en H.Von HesbergP.Zanker eds., Römische Gräberstrassen.Selbstdarstellung-Status-Standard, München, 1987, 125-138.

BöSCHUNG, D., 'Die republikanischen und frühkaiserzeitlichen Nekropolen vor den Toren Ostias", en H.Von Hesberg-P.Zanker eds., Römische Gräberstrassen. Selbstdarstellung-Status-Standard, München, 1987, 111-124.

CAMBI, N., "Salona und seine Nekropolen", en H.Von Hesberg-P.Zanker eds., Römische Gräberstrassen. Selbstdarstellung-Status-Standard, München, 1987, 251-279.

CÉBEILlaC, M., ',Quelques inscriptions inédites d'Ostie. De la République à l'Empire", M.E.F.R., 83,1971, 39-125.

CURChIN, L.A., "Vici and Pagi in Roman Spain", R.E.A., LXXXVII, 3-4, 1985, 327-343.

Dall'Olio, G., Iscrizioni sepolcrali romane scoperte nelValveo del Reno presso Bologna, Bologna, 1922.

(17) Según Rossi $(1975,157)$, es muy factible que estas sanciones, que afectaban solamente a los sepulcros familiares, equivaliesen a la pena prevista en el edicto pretorio de la actio de sepulchro violato para los violadores de los sepulcros hereditarios,aunque epigráficamente nada se indica al respecto. Dicho edicto preveía una multa entre 100/200.000 sestercios. 
D'Ambrosio-De CARo, A., "La necropoli di Porta Nocera. Campagna di scavo 1982", en H.Von Hesberg-P.Zänker eds., Römische Gräberstrassen. Selbstdarstellung-Status-Standard, München, 1987, 199-228.

DE VISSCHER, F., Le droit des tombeaux romains, Milán, 1963.

Donat, A., "Cippi e misure dei sepolcreti romani di Bologna", Strenna Storica Bolognese, XV, 1965, 89-97.

D’Ors, A., Epigrafía Jurídica de la España Romana, Madrid, 1953.

-, "La condición jurídica del suelo en las provincias de Hispania", Atti del Cong.Int. "1 diritti locali nelle province romane con particolare riguardo alle condizioni giuridiche del suolo ", Roma, 1974, 253-268.

Duncan-Jones, R., The Economy of the Roman Empire. Quantitative Studies, Cambridge Univ. Press, 1982.

ECK, W., "Römische Grabinschriften. Aussageabsicht und Aussagefähigkeit im funerären Kontext", en H.Von Hesberg-P.Zänker eds., Römische Gräberstrassen. Selbstdarstellung-Status-Standard, München, 1987, 61-83.

GERACI, G., 'Note di diritto sepolcrale romano:dalla collezione di epigrafi urbane già nella Rocca di Cusercoli”, Studi Romagnoli, 20, 1969, 375-413.

KePpIE, L., Colonisation and Veteran Settlement in Italy 47-14 B.C., Roma, 1983.

LeVEau, Ph., "Nécropoles à Caesarea de Maurétanie", en H.Von Hesberg-P.Zanker eds., Römische Gräberstrassen. Selbstdarstellung-Status-Standard, München, 1987, 281-290.

MeigGs, R., Roman Ostia, Oxford, 1985.

ORTALLi, J., "La Via dei Sepolcri di Sarsina. Aspetti funzionali, formali e sociali", en H.Von Hesberg-P.Zanker eds., Römische Gräberstrassen. Selbstdarstellung-Status-Standard, München, 1987, 155-182.

Purcell, N., "Tomb and Suburb", en H.Von Hesberg-P.Zanker eds., Römische Gräberstrassen. Selbstdarstellung-Status-Standard, München, 1987, 25-41.

REUSSER, Ch., 'Gräberstrassen in Aquileia", en H.Von Hesberg-P.Zanker eds., Römische Gräberstrassen. Selbstdarstellung-Status-Standard, München, 1987, 239-249.

Robinson, O., "The Roman law on burials and burial grounds", The Irish Jurist, X, 1975,175-186.

RodRÍGUEZ NeILA, J.F.' 'A portaciones epigráficas.I.", Habis, 14, 1983, 153-192.

Rossi, A.M., 'Ricerche sulle multe sepolcrali romane", R.S.A., V, 1975,111-160.

SAntero, I JA., Asociaciones Populares en Hispania Romana, Sevilla, 1978.

STEENBY, E. M., "La necropoli della Via Triumphalis", en H.Von Hesberg-P.Zanker eds., Römische Gräber Strassen. Selbstdarstellung-Status-Standard, München, 1987, 85-110.

STYLOW, A.U., 'Inscripciones latinas del sur de la provincia de Cordoba", Gerión, I, 1983, 267-303. 


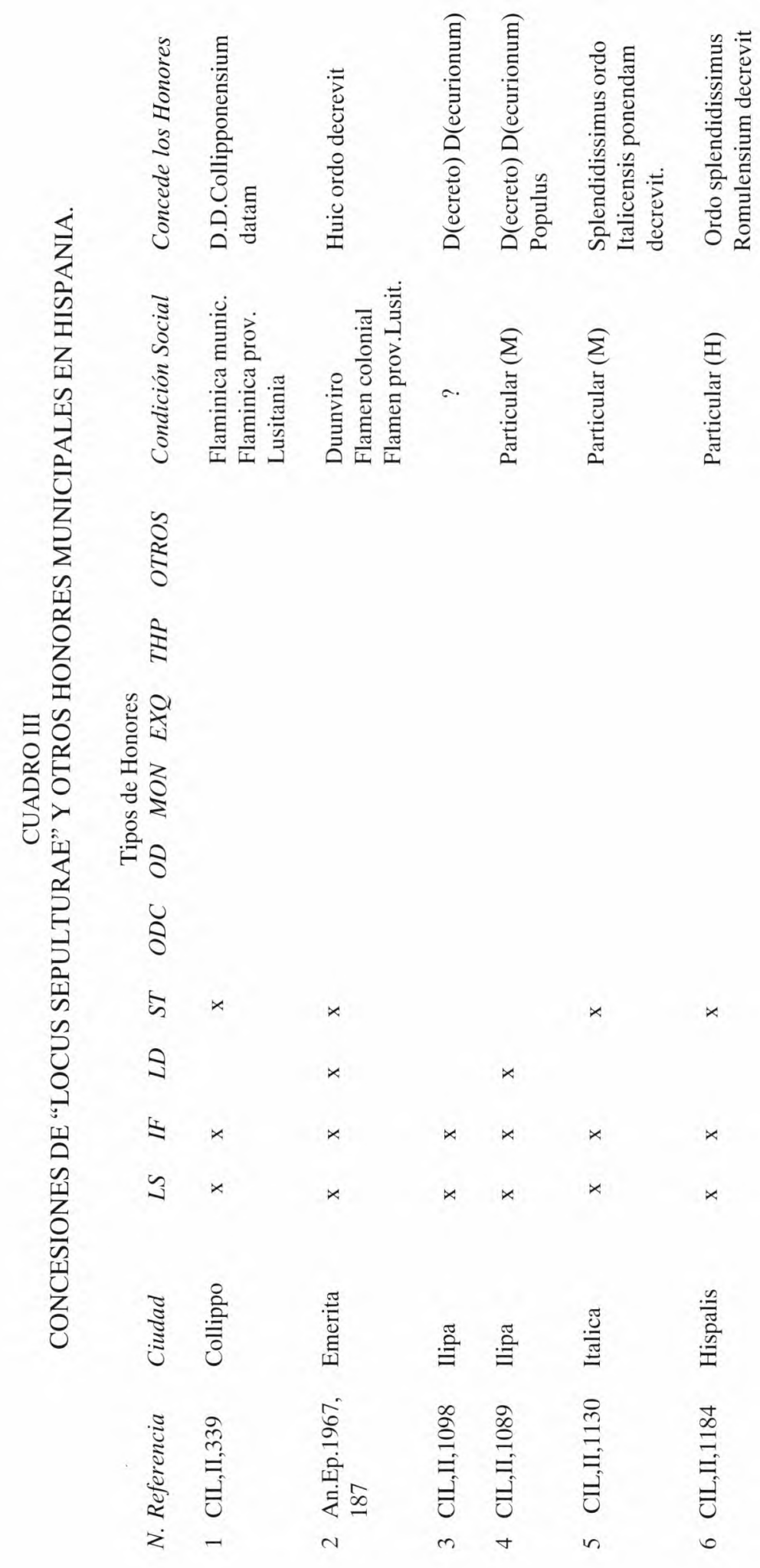




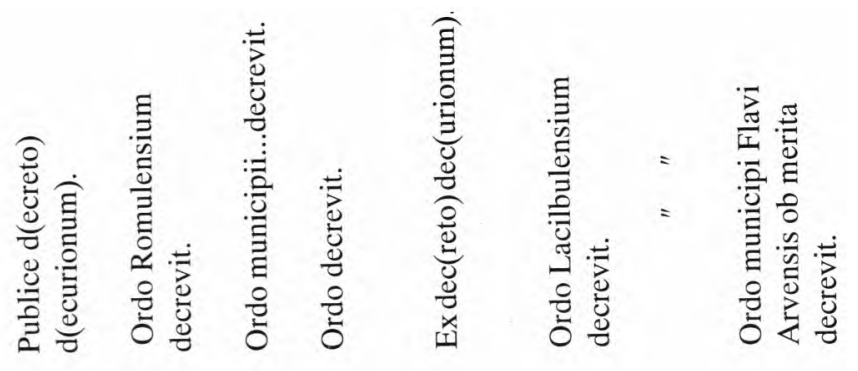

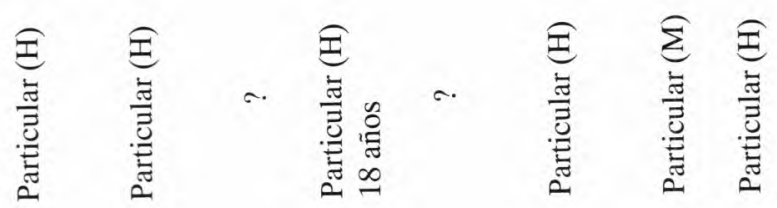

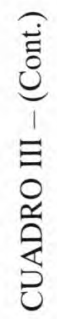

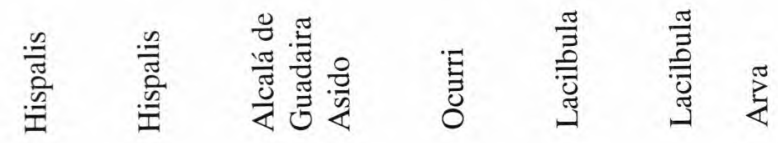

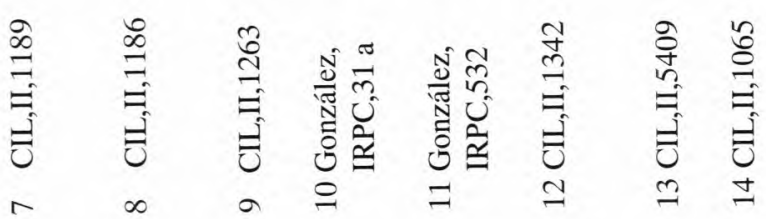




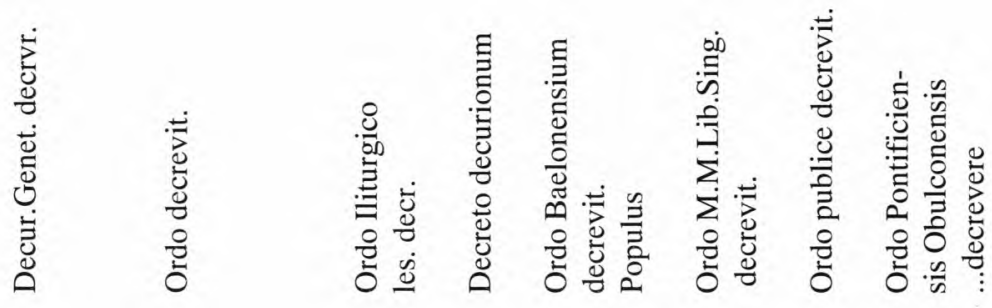

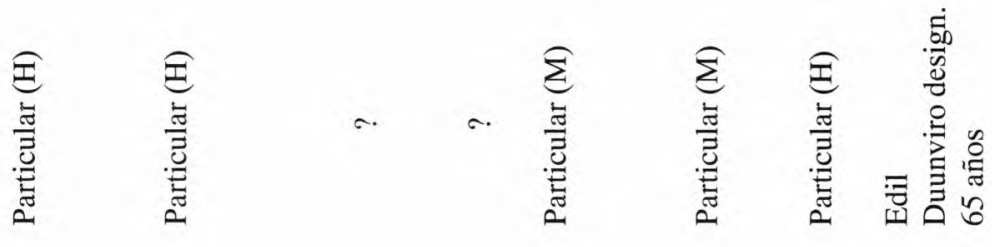

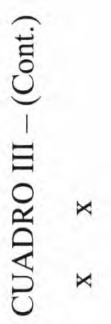

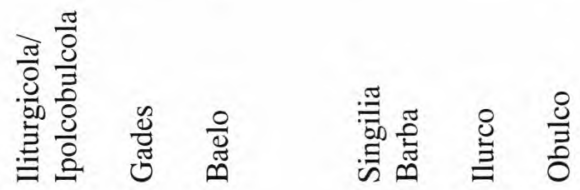

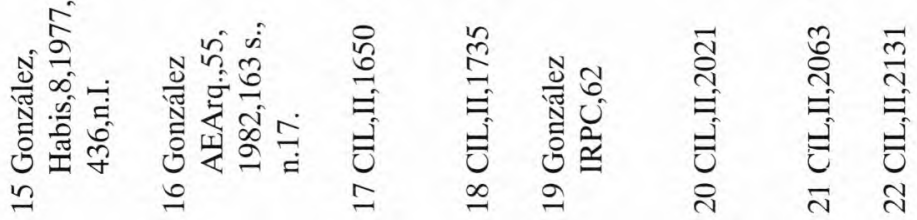




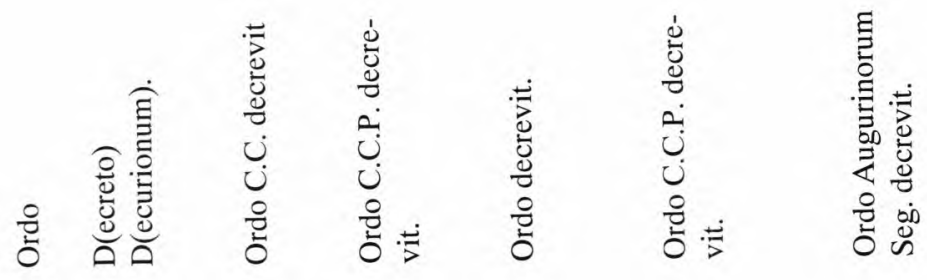

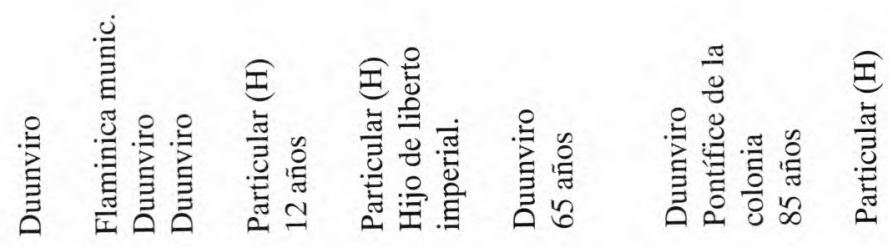

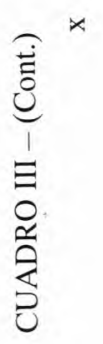

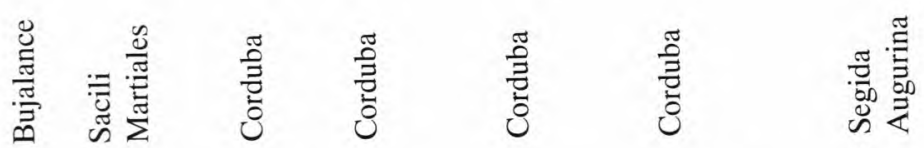

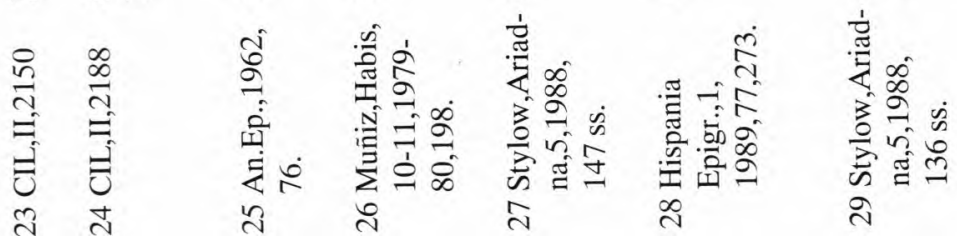




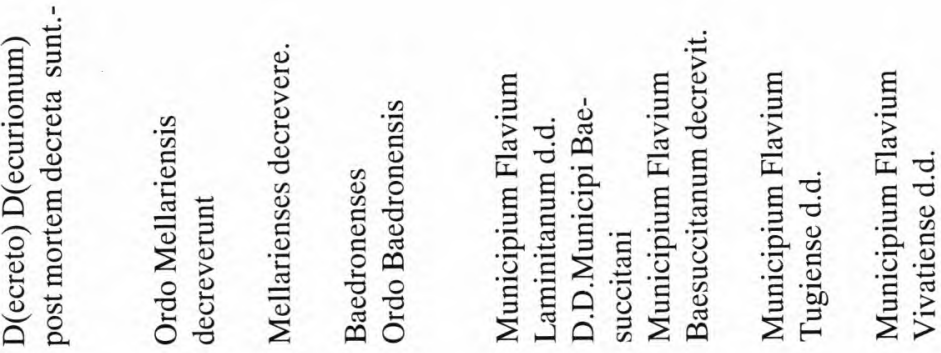

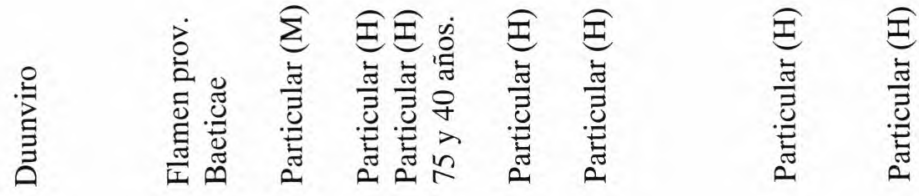

鲎

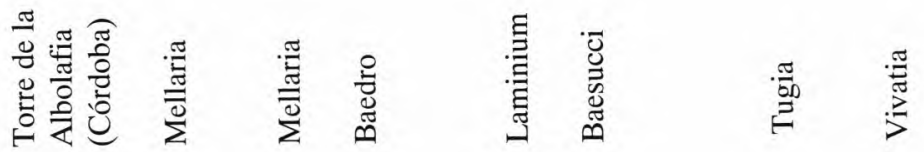

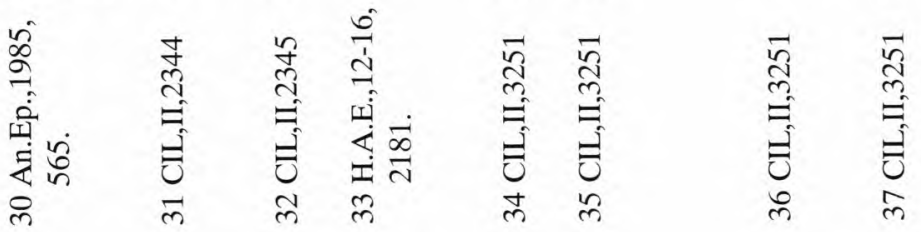




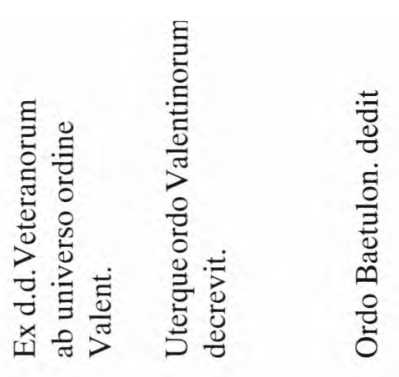

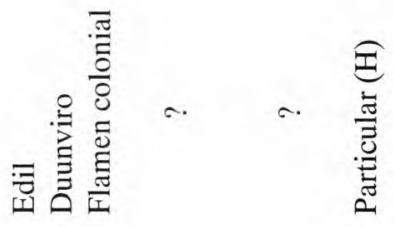

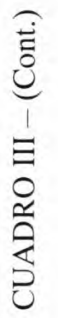

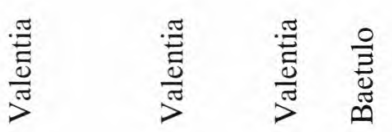

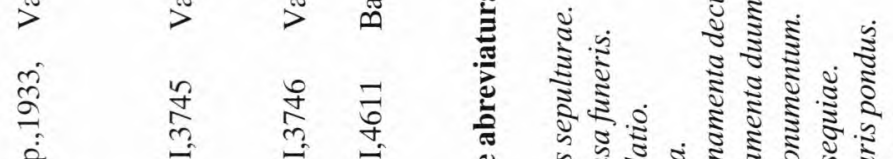

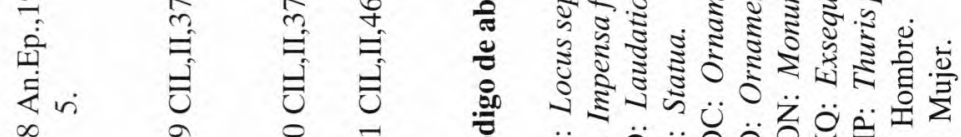

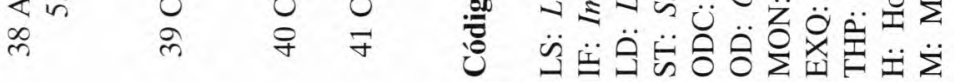




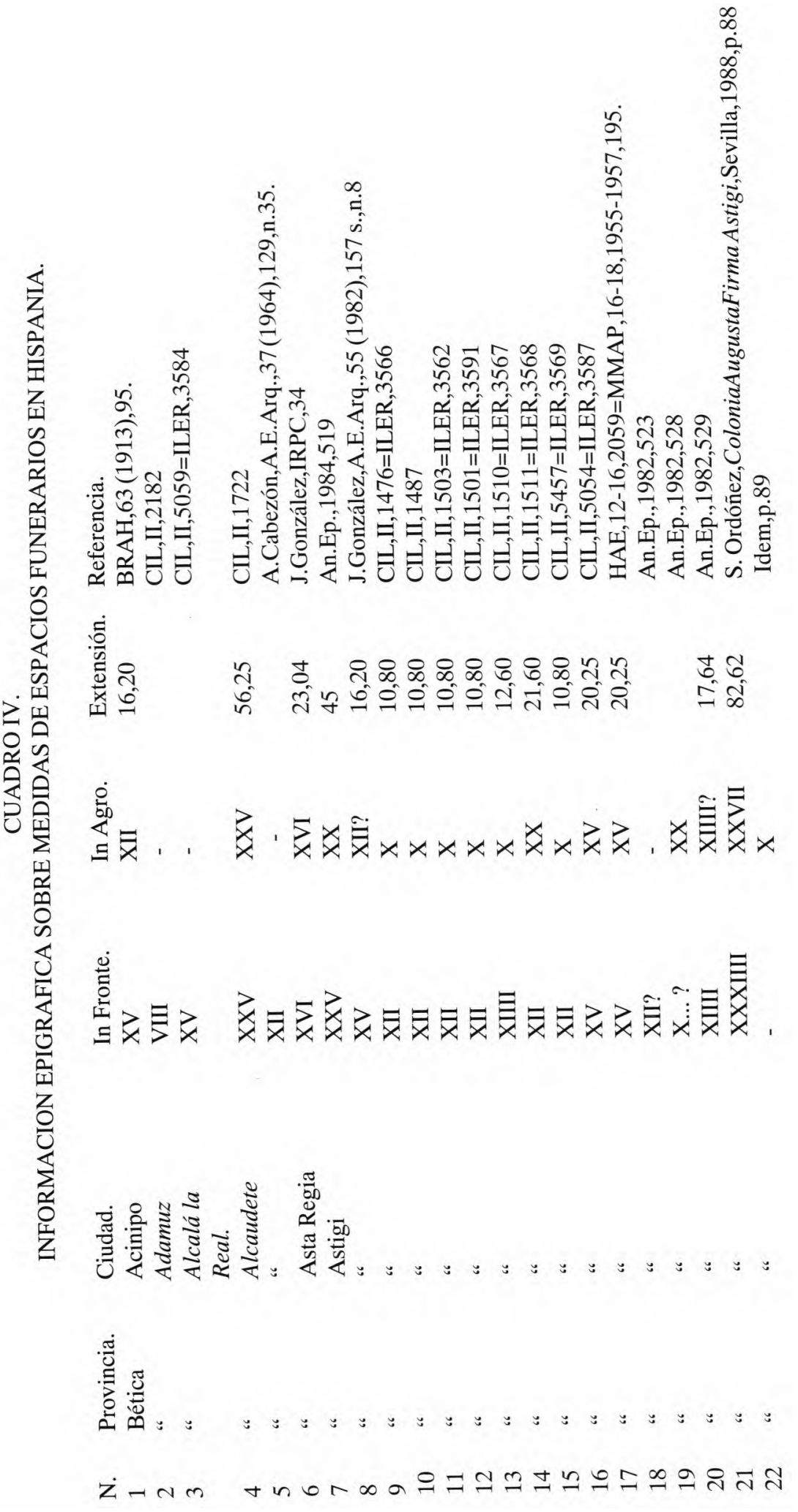




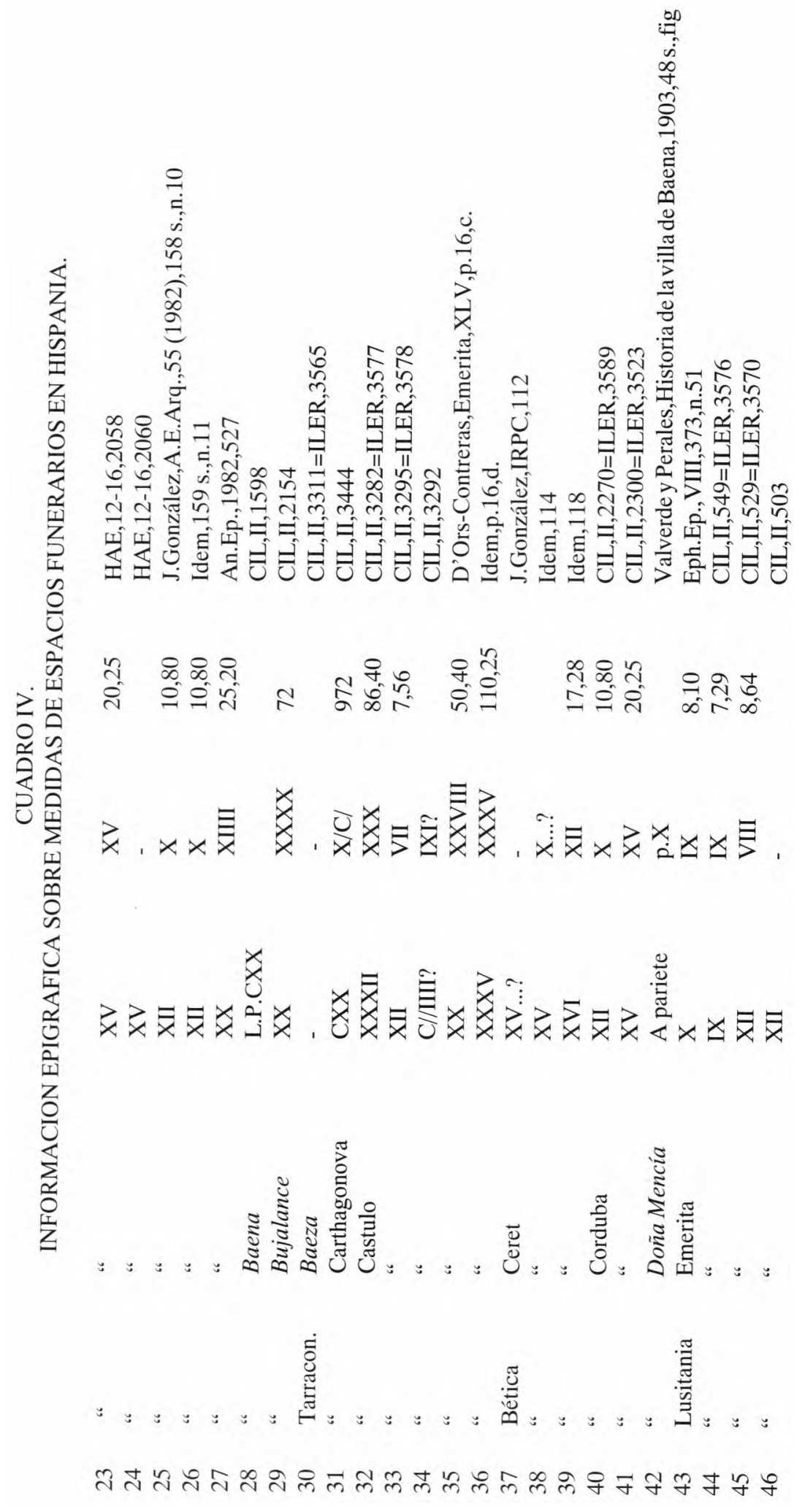




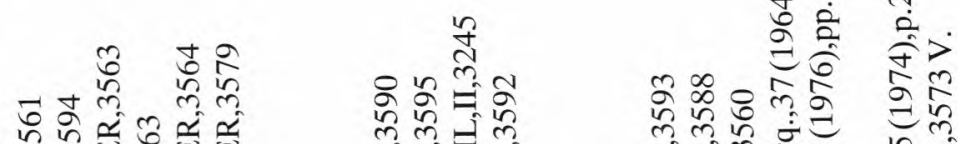

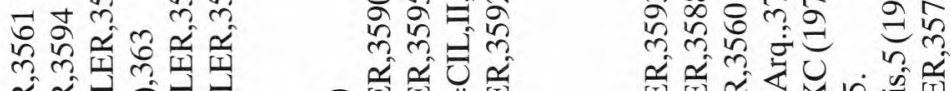

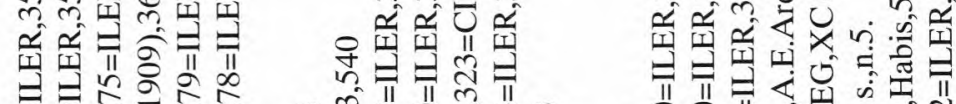

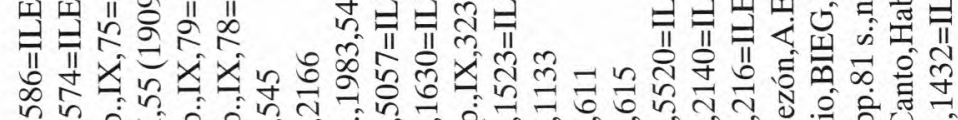

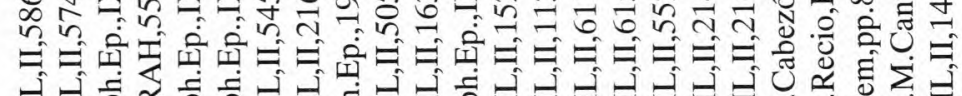

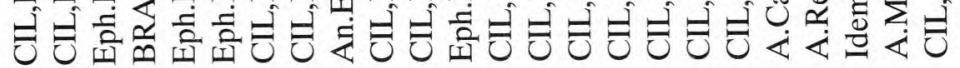

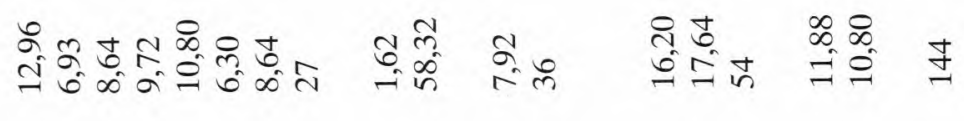
空

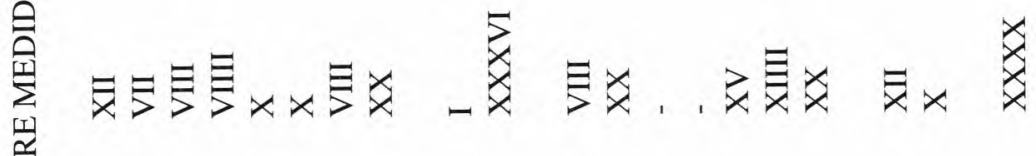

。ํㅇ

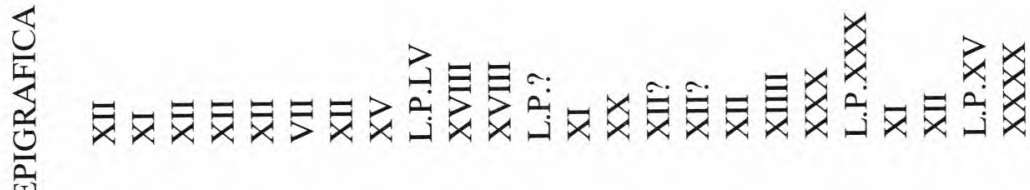

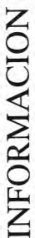

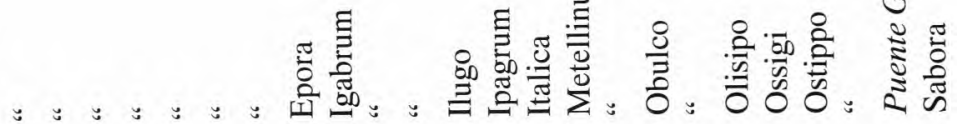

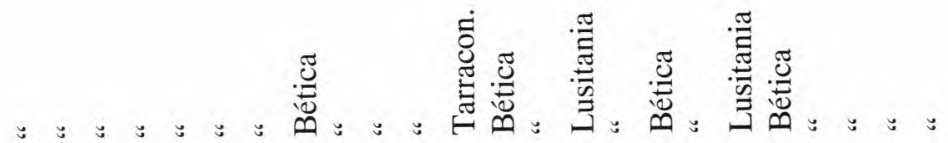

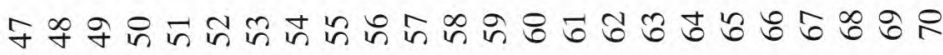




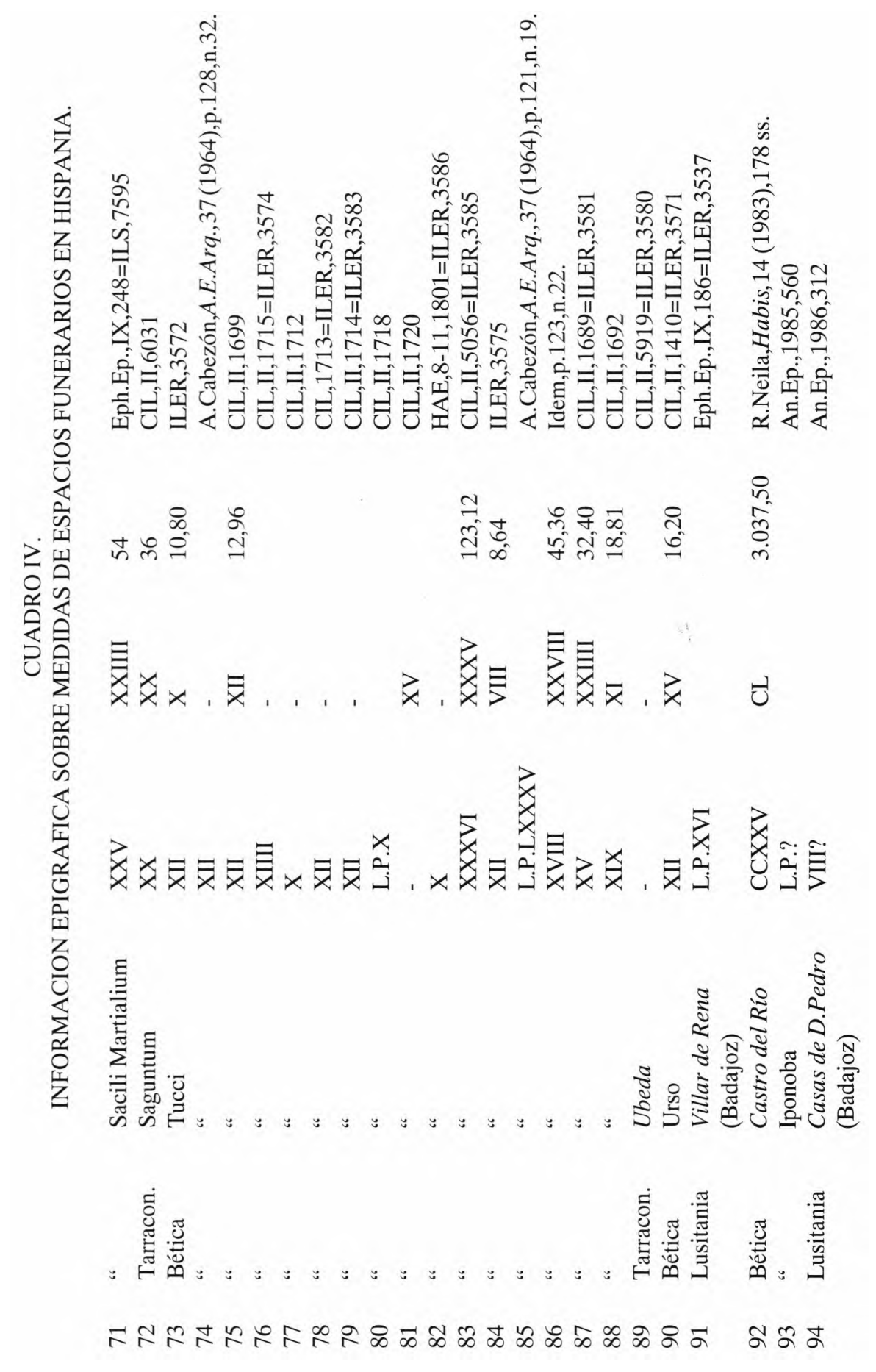

